PONTIFÍCIA UNIVERSIDADE CATÓLICA DO RIO DE JANEIRO

\title{
A realização de campanhas de promoção em ambientes econômicos desfavoráveis no mercado segurador brasileiro
}

\section{Pablo Andres Ferreira de Souza}

Trabalho de Conclusão de Curso

\author{
CENTRO DE CIÊNCIAS SOCIAIS - CCS \\ DEPARTAMENTO DE ADMINISTRAÇÃO \\ Graduação em Administração de Empresas
}




\section{Pablo Andres Ferreira de Souza}

\section{A realização de campanhas de promoção em ambientes econômicos desfavoráveis no mercado segurador \\ brasileiro}

Trabalho de Conclusão de Curso

Trabalho de Conclusão de Curso, apresentado ao programa de graduação em Administração da PUC-Rio como requisito parcial para a obtenção do titulo de graduação em Administração.

Orientador(a) : Marina Frid 
"Felizes os que promovem a paz, porque serão chamados filhos de Deus."

(Jesus Cristo) 


\section{Agradecimentos}

Minhas palavras de gratidão em primeiro lugar são para Deus, que me permitiu chegar até essa etapa da minha vida e esteve ao meu lado em absolutamente todos os momentos. Certamente posso dizer que melhores são os caminhos e os sonhos dele do que os meus.

Agradeço também aos meus pais, à minha vó e à minha irmã pela dedicação incondicional, cuidado e amor que formaram meu caráter e me ensinaram o caminho mais precioso que existe. Posso dizer que fui privilegiado em ter uma família tão especial.

O meu muito obrigado também vai para todos que colaboraram diretamente com este trabalho, não podendo deixar de citar a grande disponibilidade que tive da minha orientadora Marina Frid, Priscila Yabuta e Paulo Tercero, juntamente com quem possibilitou o contato: Fernanda Tercero e Felipe Conceição. Além disso, é uma bela oportunidade de reconhecer que sem cada professor que tive ao longo da vida eu com certeza não teria chegado aqui.

Sou grato à minha namorada que me faz ter sonhos ainda maiores e aos meus amigos que indiretamente deram sua contribuição, me motivando, dando sugestões e realmente se preocupando com o andamento do trabalho. Alguns deles sendo presentes que PUC me deu, até um amigo mais chegado que um irmão. 


\section{Resumo}

DE SOUZA, Pablo Andres F.. A realização de campanhas de promoção em ambientes econômicos desfavoráveis no mercado segurador brasileiro. Rio de Janeiro, 2017. 36 p. Trabalho de Conclusão de Curso - Departamento de Administração. Pontifícia Universidade Católica do Rio de Janeiro.

Este estudo tem como principal foco a ação que certas empresas adotam em meio a momentos de crise econômica que é cortar verbas do orçamento destinado à divulgação e à campanhas da marca tendo em vista a dificuldade de obter resultados financeiros satisfatórios em momentos como esse. Para avaliar se o corte é uma medida correta ou não, foi distribuído um questionário no qual pessoas forneciam suas preferências de consumo, além de terem a lembrança de marcas de seguradoras testada e avaliação de anúncio. Com as respostas somadas às opiniões de especialistas da área, foi possível averiguar se elas continuavam sendo as maiores do setor pelo fato de serem reconhecidas e destinarem verbas significativas para promoção.

Palavras- chave

Seguros, orçamento de comunicação, marcas de seguradoras.

\section{Abstract}

DE SOUZA, Pablo Andres F.. Execution of promotional campaigns in unfavorable economic contexts in the brazilian insurance market. Rio de Janeiro, 2017. 36 p. Undergraduate Thesis - Business Department. Pontifical Catholic University of Rio de Janeiro.

This study has as main focus the action that some companies adopt in moments of economic crisis that is to cut funds from the budget destined to publicity and to campaigns of the brand, in view of the difficulty to obtain satisfactory financial results in moments like this one. To assess whether the cut is a correct measure or not, a questionnaire was distributed to people providing their consumer preferences, as well as reminder branded insurers tested and ad evaluation. With the answers added to the opinions of specialists in the area, it was possible to find out if they remained the largest in the sector because they were recognized and allocated significant funds for promotion.

\section{Key-words}

Insurances, communication budget, brands of insurers. 


\section{Sumário}

10 tema e o problema de estudo 1

1.1. Introdução ao tema e ao problema do estudo 1

1.2. Objetivo do estudo 2

1.3. Objetivos intermediários do estudo 2

1.4. Delimitação e foco do estudo 2

1.5. Justificativa e relevância do estudo 3

2 Referencial Teórico 4

2.1. Posicionamento 4

2.2. Brand Equity 5

2.3. Publicidade e Propaganda 8

2.4. Gestão de Relacionamento com o Cliente 9

2.5. Atitude do consumidor frente às ações promocionais 11

3 Métodos e procedimentos de coleta e de análise de dados do estudo 13

3.1. Definição e processo de pesquisa 13

3.2. Tipos de pesquisa 15

3.3. Relevância das entrevistas e do questionário 16

3.4. Detalhes e limitações do Estudo 17

4 Apresentação e análise dos resultados 18

4.1. Entrevistas 18

4.2. Descrição do perfil da amostra 21

4.3. Questionário 23

4.3.1. Questões introdutórias 24

4.3.2. Teste de lembrança 29

4.3.3. Avaliação de anúncios 31

5 Conclusões e recomendações para novos estudos 35

6 Referências Bibliográficas 38 


\section{Lista de Gráficos}

Gráfico 1: Composição etária da amostra: aproximadamente $64 \%$ dos respondentes tem entre 18 e 34 anos ..................................................... 21

Gráfico 2: Escolaridade da amostra: $47 \%$ têm pelo menos o Ensino Médio

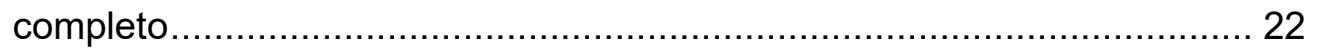

Gráfico 3: Distribuição de renda da amostra: 46\% são da Classe C................. 23

Gráfico 4: Top of Mind: as marcas mais lembradas foram SulAmérica, Bradesco

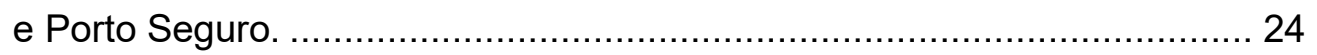

Gráfico 5: Respondentes com seguros: $73 \%$ da amostra possui algum tipo de seguro.

Gráfico 6: Importância dos seguros: 95\% dos respondentes consideram o seguro como um produto importante ............................................................... 26

Gráfico 7: Momento de aquisição: A amostra acredita que o seguro deve ser adquirido desde a juventude.............................................................. 27

Gráfico 8: Atributos de um seguro: a amostra prioriza a qualidade do seguro ... 28

Gráfico 9: Contratação de seguradora: Com base nos anúncios, qual seguradora seria contratada ou não................................................................... 33

Gráfico 10: Público-alvo das seguradoras: Com base nos anúncios, qual a seguradora que visou mais o público de mais ou de menos idade. 34 


\section{Lista de Tabelas}

Tabela 1: Relação dos níveis de construção de relacionamento com o cliente e a rentabilidade obtida - Fonte: Kotler e Keller (2009), "Administração de Marketing". 11

\section{Lista de Figuras}

Figura 1: Estrutura para o posicionamento da marca. - Fonte: Adaptado de Crescitelli e Shimp (2012), “Comunicação de Marketing”, p 120................. 7 Figura 2: Processo de pesquisa. - Fonte: Malhotra (2006), "Pesquisa de

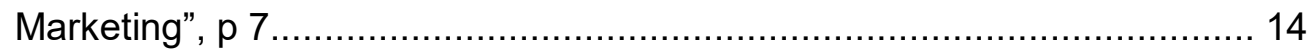

Figura 3: Anúncio de apresentação da Youse, plataforma de vendas da Caixa

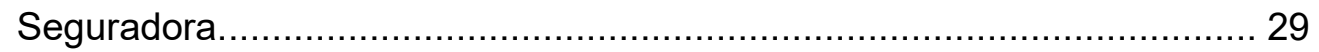

Figura 4: Seguro automotivo Bradesco no teste de lembrança. ....................... 29

Figura 5: Slogan e cores da SulAmérica no teste de lembrança...................... 30

Figura 6: Anúncio da Bradesco. ........................................................... 31

Figura 7: Anúncio da SulAmérica. .............................................................. 31

Figura 8: Anúncio da Banco do Brasil Mapfre.............................................. 32

Figura 9: Anúncio da Youse Caixa Seguradora.......................................... 32 


\section{0 tema e o problema de estudo}

\subsection{Introdução ao tema e ao problema do estudo}

O contexto globalizado no qual nossa sociedade está inserida nos dias de hoje permite que as pessoas tenham exposição instantânea e contínua a ações publicitárias e experiências com diversas marcas do mercado, algo que se intensifica à medida que os anos têm passado e serve como tema de estudo para pensadores contemporâneos importantes como Manuel Castells (1999). De acordo com a Associação dos Profissionais de Propaganda do Brasil, o investimento publicitário brasileiro alcançou a totalidade de $\mathrm{R} \$ 132$ bilhões em 2015 e, diante de um número tão relevante, a necessidade de compreender de que forma as empresas obtém retorno torna-se um tema de estudo de interesse de muitos alunos, professores e profissionais da comunicação, de modo que suas ações possam ser melhor embasadas e mais específicas a fim de atingir com maior êxito o seu público-alvo.

Como área de estudo importante e bastante aplicável nas rotinas das empresas, a Comunicação comumente sofre com indagações quanto à mensuração de seu resultado frente aos investimentos feitos nela. Tal situação desencadeia outra que é a adoção de conservadorismo na disposição de recursos financeiros nos orçamentos das áreas de comunicação nas empresas a ponto de impedir muitas vezes a continuidade de ações realizadas há certo período de tempo, justamente por ser difícil a mensuração do impacto dessas ações nas receitas das organizações.

Um mercado consistente e importante para o Brasil é o de seguros e que será o foco deste trabalho. Segundo a Superintendência de Seguros Privados, a SUSEP, o faturamento do mercado em 2015 foi de aproximadamente R\$ 218 bilhões e tal número mostra a representatividade das ações das seguradoras no nosso mercado. Considerando os dados apresentados, de que maneira a 
comunicação integrada de uma empresa impacta na rentabilidade obtida em um produto ou serviço e no crescimento do seu brand equity?

\subsection{Objetivo do estudo}

Este trabalho tem como objetivo final avaliar, com base nos conceitos de comunicação integrada de marketing de Crescitelli e Shimp (2012), se vale a pena continuar fazendo investimentos em divulgação da marca mesmo em cenários de dificuldade macroeconômica, além de avaliar se existe elevação do brand equity das marcas que serão apresentadas no item 4 deste capítulo. Crescitelli e Shimp (2012) argumentam que, embora a mensuração dos impactos desses investimentos seja difícil, ela não é impossível, e é melhor realizá-la do que simplesmente desconsiderá-la. Dessa forma, com a realização da mensuração, os esforços de comunicação serão fundamentados em dados que mostram a importância da promoção, mesmo em cenários econômicos adversos, para ainda assim trazer ganhos tanto tangíveis, maior receita de vendas, por exemplo, como ganhos intangíveis de melhora na reputação e identificação com a marca.

\subsection{Objetivos intermediários do estudo}

Para esta tarefa, os objetivos intermediários são:

- Avaliar o relacionamento estabelecido entre o cliente e a marca à medida que slogans e anúncios são apresentados;

- Apresentar como o processo da mensuração dos resultados das ações é feito pelas empresas;

- Entender as preferências do consumidor diante da exposição das ações de empresas concorrentes;

- Verificar se existe lealdade pela marca e, como isso, se há impacto no brand equity.

\subsection{Delimitação e foco do estudo}

O estudo elaborado tem como foco o mercado brasileiro de seguros, mais especificamente as 3 maiores seguradoras do mercado em 2015, de acordo com o Sindicato de Corretores de Seguros do Rio de Janeiro, sendo elas Bradesco Seguros, Banco do Brasil Mapfre e SulAmérica, além da Youse que é uma nova plataforma de vendas da Caixa Seguradora e será inserida neste trabalho por ter 
propostas para atingir um público mais jovem, além de permitir que seu cliente resolva tudo o que é necessário por meio de seu smartphone, características que serão comparadas com às 3 primeiras seguradoras.

Outros pontos importantes da delimitação é que este estudo contará com duas entrevistas de pessoas envolvidas no mercado se seguros e não pesquisará pessoas de todo país, se restringindo majoritariamente a pessoas do Rio de Janeiro que tiverem acesso ao questionário, algo que será melhor delimitado no capítulo 3 e também que, em meio a tantas possibilidades de informações que o consumidor pode conceder, este trabalho visa basicamente saber como se dá o seu relacionamento com as seguradoras citadas e como isso implica em retorno financeiro para elas. Dessa forma, analisar a atitude dos consumidores frente as campanhas institucionais é uma questão-chave.

\subsection{Justificativa e relevância do estudo}

As informações que o estudo pretende produzir são de interesse do mercado segurador corporativo que podem ser utilizadas para remodelar os modelos existentes tanto para alcançar os clientes por meio das ações publicitárias como também medir o efeito que elas causam em suas receitas, buscando estabelecer uma melhor equação de ganhos.

As seguradoras voltadas para relacionamento com o cliente poderão usufruir dos dados aqui extraídos, uma vez que os interessados em desenvolver uma marca e boas experiências com o cliente são geralmente empresas que costumam destinar uma parte considerável de seu orçamento em promoção acreditando que uma boa reputação também gera ganhos financeiros para a companhia e influenciando positivamente $o$ valor percebido pelos seus consumidores.

A relevância deste estudo também servirá ao público acadêmico uma vez que haverá a aplicação dos conceitos apresentados em um mercado importante, mas pouco estudado. Os dados provenientes da pesquisa a ser realizada poderão ser utilizados como base e ponto de partida para novas pesquisas sobre o mercado segurador. 


\section{Referencial Teórico}

\subsection{Posicionamento}

De acordo com um clássico da literatura do marketing, Kotler e Keller (2009) definem o posicionamento como a ação de projetar o produto e a imagem da empresa para ocupar um lugar diferenciado na mente do público-alvo. Segundo os autores, o desenvolvimento de uma boa e eficaz estratégia de posicionamento é oriunda de uma segmentação e seleção do público-alvo bem realizadas, acreditando que, caso contrário, se o passo-a-passo da estratégia de marketing não for bem estruturado, haverá problemas quanto ao entendimento da proposta do produto por parte do mercado. A falta de clareza impacta negativamente os resultados de receitas, lucratividade e valorização da marca.

Prosseguindo com seu enfoque no produto e na imagem da empresa, Kotler e Keller (2009) também defendem que uma estratégia de marketing bem estruturada é capaz de gerar uma vantagem potencial para a empresa na geração de valor para o cliente, o que remete muito aos conceitos ligados à cadeia de valor apresentada por Michael Porter em 1985. Uma vez que a vantagem potencial é adquirida, torna-se teoricamente mais fácil ter ganhos de mercado superiores aos dos concorrentes, possibilitando um aumento da participação daquele mercado e elevação do valor da marca, um dos principais aspectos deste trabalho.

Como característica marcante em uma estratégia de posicionamento, Kotler e Keller (2009) apresentam a necessidade de se identificar e trabalhar com os pontos de diferença e os pontos de paridade existentes, a fim de se estabelecer uma estrutura de referência competitiva que fundamentará a estratégia adotada. Segundo eles, os pontos de diferença são qualidades e benefícios que os consumidores associam fortemente ao produto ou à marca, sendo avaliados positivamente e acreditam quase ser incomparáveis, ou pelo menos muito difíceis de serem alcançados, com os produtos da concorrência. Essas fortes associações designam características únicas ao produto lhe conferindo quase que uma identidade existente na mente do consumidor, algo que será melhor 
apresentado um pouco mais adiante. Enquanto isso, os pontos de paridade são associações que podem ser compartilhadas com outros produtos, muitas vezes tipicamente por serem pertencentes a um mesmo segmento do mercado. Embora não constituam diferenciação, são essenciais, porque representam requisitos mínimos para que o consumidor os considere em sua compra, sendo incoerente em uma estratégia de posicionamento um produto possuir pontos de diferença percebidos e os pontos de paridade serem inexistentes, a menos que esses produtos sejam inovações de ruptura. De acordo com Levitt (1991), inovações de ruptura são aquelas com aplicações práticas no cotidiano e que não possuíam qualquer outro produto parecido antes e que pudesse ser comparado.

De forma complementar, Al Ries e Jack Trout (1989), apresentam o posicionamento como algo relacionado não a uma estratégia necessariamente centralizada no produto, mas sim com o que se faz na mente do cliente em perspectiva, posicionando o produto na mente do comprador em potencial. Sob seu ponto-de-vista, eles mostram que mudanças feitas no nome, no preço ou na embalagem não são mudanças feitas no produto, mas sim mudanças "cosméticas" com o intuito de assegurar uma posição de valor na mente do consumidor.

Outro ponto trabalhado por Ries e Trout (1989) apresenta o nosso mercado com propagandas e informações em excesso, fazendo com que nossa sociedade seja saturada em comunicação. A partir disso, fica difícil para o consumidor médio reter informações acerca dos produtos e marcas, de modo que sua mente se vê obrigada a simplificar os dados recebidos, agindo como um filtro e descartando aquilo que não foi bem definido, caracterizado ou tido como interessante por ele. Como medida para ser eficaz, os autores defendem uma forma de mensagem mais simplificada possível, concentrando-se nas características do produto que possam ter um alcance melhor em detrimento a outras que o compõem, mas não chegariam no mesmo objetivo.

\subsection{Brand Equity}

Segundo David A. Aaker (1998), o termo brand equity pode ser definido como um conjunto de ativos e passivos ligados a uma marca, seu nome e seu símbolo, que se somam ou se subtraem do valor proporcionado por um produto ou serviço para uma empresa e/ou para os consumidores dela. Levando em conta esta definição, é importante salientar que os ativos e passivos 
mencionados poderão impactar positiva ou negativamente a marca a qual estão relacionados uma vez que os mesmos sofram algum tipo de modificação.

Em sua introdução ao conceito do brand equity, Aaker (1998) disserta sobre a história do Ivory, um sabão lançado em 1881 pela $P \& G$ que foi divulgado possuindo o posicionamento de ser puro, suave, flutuante e de cor branca, atributos que o diferenciaram substancialmente dos demais sabões existentes na época. Tal estratégia permitiu que os consumidores percebessem o Ivory (marfim, em inglês) como um produto superior e os intensos esforços com propaganda fizeram com que a marca fosse reforçada na mente das pessoas. Este exemplo, como o próprio Aaker (1998) sugere, mostra como o desenvolvimento do brand equity proporcionou que a $P \& G$ estabelecesse características que definissem a posição de mercado de seu produto, bem como a persistir por longos períodos de tempo e a resistir à concorrência agressiva que viria posteriormente.

Diante disto, podemos notar que é necessário que uma estratégia, para atribuir valor a uma marca e elevar o seu brand equity, possua características que visem à construção de ações de longo prazo, busque fazer com que a marca esteja em contato regular com as pessoas e invista em uma presença constante na mente das pessoas, algo importante a ser seguido pela maioria das empresas no mercado brasileiro. A propósito, o brand equity possui duas perspectivas e que apresentam características distintas, mas que convergem na construção e percepção de valor de uma marca, como propõem Crescitelli e Shimp (2012) e destrincharemos a seguir.

De acordo com Crescitelli e Shimp (2012), uma perspectiva existente acerca do brand equity é sob a ótica da empresa, considerando-o como um "ativo da marca", algo quantificável, um verdadeiro patrimônio e que é um resultado obtido por meio dos esforços empregados a fim de gerar valor para a marca. Com isso, à medida que há geração de valor de uma marca, quatro entre muitos resultados positivos acontecem sendo eles: a) Alcançar maior participação de mercado; b) Aumentar a lealdade à marca; c) Obter capacidade de cobrar um preço mais alto que a concorrência; e d) Ganhar receita adicional. Como delimitado antes no capítulo 1, embora as implicações sejam muitas, este estudo visa analisar exclusivamente o relacionamento dos consumidores com as seguradoras (Bradesco, SulAmérica, Banco do Brasil Mapfre e Caixa Seguradora) e o retorno financeiro que pode ser revertido a elas.

Ainda segundo Crescitelli e Shimp (2012), a outra perspectiva existente acerca do brand equity está sob a ótica do consumidor, o qual enxerga numa 
marca um valor que a pessoas estão familiarizadas com ela e guardam em suas respectivas memórias associações únicas com a marca. Por meio das associações, são obtidos pensamentos e sentimentos específicos que os consumidores ligam em suas memórias sobre as marcas. Além desse modo de encarar a perspectiva do consumidor, Crescitelli e Shimp (2012) apresentam outro modo de pensar a respeito do brand equity que se fundamenta em duas formas de conhecimento sendo elas: a percepção da marca e a imagem da marca.

A percepção da marca está relacionada com a existência dela em nossas mentes, sendo evocada e reforçada pelas ações de promoção, as quais nos permitem o reconhecimento dela, o que tem a ver com sua permanência em nossa memória com o passar do tempo e ao nível recordação dela frente às outras marcas. Notadamente, as marcas mais lembradas possuem mais valor que as que vêm depois. De forma complementar, a imagem da marca, segundo Crescitelli e Shimp (2012), representa as associações que são ativadas na memória quando as pessoas pensam sobre uma marca específica. As marcas podem ser avaliadas de acordo com seu nível de favorabilidade, força e singularidade, bem como os tipos de associações que se desmembrando considerando os atributos (ligados mix de marketing), os benefícios (relacionados ao posicionamento já discorrido na primeira seção deste capítulo) e a atitude (será trabalhada na quinta seção deste capítulo). A imagem abaixo elucida as informações apresentadas neste parágrafo.

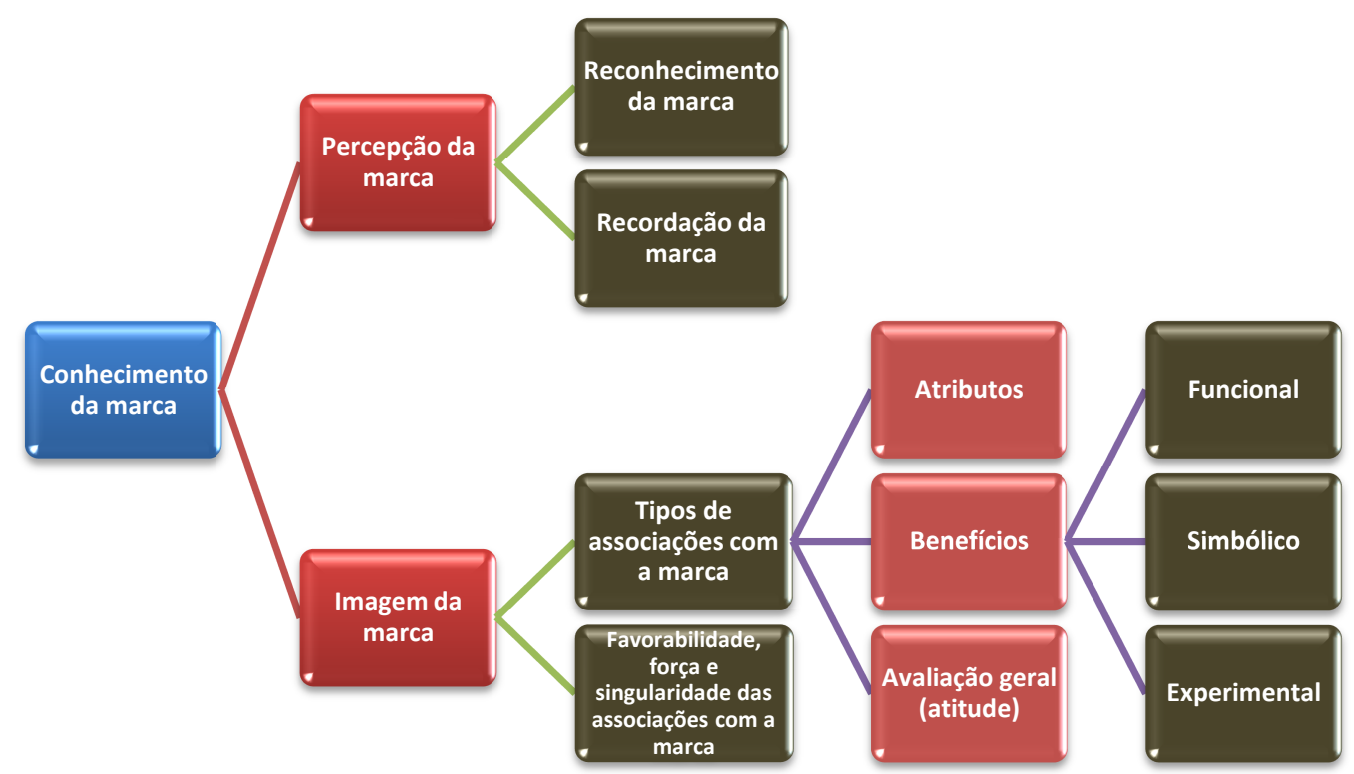

Figura 1: Estrutura para o posicionamento da marca. - Fonte: Adaptado de Crescitelli e Shimp (2012), “Comunicação de Marketing”, p 120. 


\subsection{Publicidade e Propaganda}

O conceito de publicidade e a propaganda é muito importante dentro da área de estudo do marketing e ferramenta importante para os profissionais da área sendo fundamental para promoção das marcas por parte das organizações que as detém. Partindo de um pressuposto mais teórico, Crescitelli e Shimp (2012) definem-o como uma atividade organizacional cuja função prioritária é a promoção de um bom relacionamento entre uma empresa e seus diversos públicos de interesse. Por se tratar de um relacionamento, deve ser conduzida não como algo pontual, mas sim duradouro, que busque criar vínculos com os interessados visando interações tidas como "ganha-ganha", onde ambos os lados saem favorecidos e satisfeitos, mas é algo que será melhor abordado mais adiante na seção de Gestão de Relacionamento com o Cliente.

Os autores ainda acrescentam que a publicidade e propaganda têm também como objetivo a opinião pública e não necessariamente apenas o consumidor, embora suas ações de qualquer forma exerçam influência sobre ele mesmo que de forma indireta. Justamente por isso, as ações de publicidade espontânea tendem a ter mais credibilidade na mente do consumidor do que propriamente os esforços da propaganda paga, já que é comum atribuir mais confiança ao que reportagens e a opinião pública dizem de algo do que um anúncio de uma propaganda de uma marca falando dela mesma. Além de ser formadora de opiniões, a publicidade é caracterizada por, geralmente, não ser paga e também pelo seu cunho de imparcialidade. Todavia, ela não pode ser controlada, uma vez que a imprensa pode ser favorável ou não ao que uma marca ter desempenhado e seus impactos são ainda mais difíceis de medir se comparados com os da propaganda paga.

Sob uma perspectiva mais prática, Al Ries e Laura Ries (2000) em "As 22 Consagradas Leis de Marcas", apresentam a publicidade como algo imprescindível para a inserção de uma marca no mercado, chegando a afirmar que "O nascimento de uma marca se consuma com publicidade, não com propaganda". A partir dessa aplicação do uso da publicidade e das suas características próprias já apresentadas no parágrafo anterior, fica mais fácil compreender o porquê de uma marca ter de ser capaz de gerar publicidade favorável para si e ela terá mais possibilidades de encontrar um espaço tão valorizado na mente do consumidor por parte das empresas se o que as pessoas dizem a respeito dela for bom e aceito de modo comum pela maioria. 
Vale ressaltar que enquanto houver notícias, é importante fazer bom uso da publicidade, mas, quando elas se tornarem menos frequentes, a partir daí devese explorar mais o uso da propaganda, de acordo com o que propõe os autores, de modo a criar percepções e distinções para a marca por meio da propaganda e, com isso, desenvolver imagens positivas a ela, sendo importante também para manter a participação de mercado alcançada e evitar que os concorrentes avancem sobre ela, ou até mesmo caia no esquecimento do consumidor.

Sob um ponto-de-vista antropológico, Everardo Rocha (1990) diz que a publicidade recria a imagem de cada produto $e$, atribuindo uma identidade a cada um, ela os torna particulares e estende o horizonte dos produtos sendo eles agora não limitados às relações de produção, mas alcançando também as relações humanas, simbólicas e sociais que caracterizam o consumo. A partir disso, podemos inclusive alongar as discussões acerca do poder que os produtos têm e influenciam o comportamento humano, interferindo no relacionamento com outros indivíduos por meio de suas preferências de consumo.

\subsection{Gestão de Relacionamento com o Cliente}

A Gestão de Relacionamento com o Cliente é um termo que vem do inglês Costumer Relationship Management (CRM) e é definido por Sobral (2012) como um processo estratégico de modelagem das interações entre os clientes e a organização de forma a maximizar, simultaneamente, o valor econômico do cliente para a organização e a satisfação deste. Para que este processo seja possível, é necessária a utilização de sistemas informatizados em conjunto com uma postura ou atitude da instituição a fim de administrar um bom relacionamento com os clientes, armazenando e fazendo uso adequado das informações muitas vezes fornecidas por eles mesmos, de modo que as atividades da empresa possam ser norteadas da forma correta para gerar valor nesta relação.

Com foco na abordagem dos sistemas de informação de CRM, Sobral (2012) salienta que por meio deles a organização consegue fazer uma segmentação customizada e precisa da sua base de clientes. Dessa forma, pode-se otimizar o custo de serviço de cada cliente individual, determinar quais consumidores são pouco rentáveis e tomar uma medida quanto a isso, avaliar o retorno do investimento utilizados com campanhas de marketing, aumentar 
receitas pela atração de novos clientes dentre outras vantagens da adoção do CRM.

Como o próprio autor destaca, consumidores satisfeitos tendem a adquirir outros produtos da organização por meio da satisfação com o acompanhamento da experiência, bem como são mais baratos de servir e proporcionam uma publicidade gratuita - o chamado boca-a-boca, para os outros consumidores que o conhecem, o que muitas vezes pode ser mais eficaz e muito mais barato do que uma propaganda dispendiosa. Além dessas vantagens, também é válido destacar que é mais barato manter seus clientes fidelizados do que atrair novos clientes, além de que os custos financeiros e psicológicos percebidos pelos clientes quanto a mudanças de produtos ou da própria organização podem ser minimizados e o oferecimento de condições especiais para consumidores assíduos.

A abordagem de Kotler e Keller (2009) também ressalta a importância da existência de um banco de dados bem desenvolvido e bom gerenciamento das informações a fim de fundamentar as estratégias de marketing, entretanto apresenta mais formas e posturas na prática do CRM visando a maximização da satisfação do cliente. Segundo eles, adotar uma verdadeira política de CRM exige que este princípio esteja na proposta de valor da empresa, sendo esta um conjunto de benefícios que a empresa promete entregar. Um dos meios pelo qual a empresa pode tentar cumprir sua promessa reside na gestão da qualidade total que, de acordo com os autores, é uma abordagem que busca a melhoria contínua dos processos, produtos e serviços da organização.

Além dessa abordagem, Kotler e Keller (2009) apontam também uma forma complementar visando a construção da fidelidade do cliente está nos cinco níveis de construção de relacionamento possíveis com o cliente, sendo eles: a) marketing básico (o vendedor apenas vendo o produto), b) marketing reativo (além de vender, o vendedor incentiva o cliente a ligar para tirar dúvidas), c) marketing responsável (o vendedor liga para ver as expectativas e obter feedback), d) marketing proativo (o vendedor liga de tempos em tempos para dar orientações de maximizar o uso do produto) e e) marketing de parceria (a empresa trabalha em conjunto com o cliente para descobrir meios de um desempenho melhor). A utilização deles é recomendada de acordo com a relação entre a quantidade de clientes ou distribuidores existentes e a margem obtida. A matriz a seguir elucida a compreensão do conceito. 
Tabela 1: Relação dos níveis de construção de relacionamento com o cliente e a rentabilidade obtida - Fonte: Kotler e Keller (2009), "Administração de Marketing".

\begin{tabular}{|c|c|c|c|}
\hline & MARGEM ALTA & MARGEM MÉDIA & MARGEM BAIXA \\
\hline Muitos Clientes & Responsável & Reativo & Básico ou Reativo \\
\hline $\begin{array}{c}\text { Quantidade Média de } \\
\text { Clientes }\end{array}$ & Proativo & Responsável & Reativo \\
\hline Poucos Clientes & Parceria & Proativo & Responsável \\
\hline
\end{tabular}

Todavia, embora a utilização do CRM seja em muitos casos bastante rentável, é necessário verificar a real necessidade de implantá-lo, bem como as adaptações que serão precisas para sua utilização. Não seria vantajoso, por exemplo, utiliza-lo em um mercado que os clientes são pouco fiéis à marca, também quando os custos são muito elevados e o retorno não compensa, sem falar na necessidade de que todos na empresa estejam alinhados e motivados para desempenhar tal política de relacionamento com o cliente. Vale destacar que também é desvantagem adotá-lo quando a unidade de venda é muito pequena ou até perecível, como uma bala, de acordo com a exemplificação de Kotler e Keller (2009), sendo necessário, em meio a ressalvas consideráveis, verificar se a adoção do CRM trará ganhos substanciais para a companhia.

\subsection{Atitude do consumidor frente às ações promocionais}

Mais um ponto importante para a estruturação deste trabalho, a atitude dos consumidores é definida por Solomon (2011) como uma avaliação duradora e geral das pessoas, objetos, propagandas ou questões. Além dela, temos o objeto de atitude que é qualquer coisa em relação a ela mesma que desenvolvemos uma atitude. Solomon (2011) afirma que ela é duradoura porque não tende a mudar tão fácil e rapidamente ao longo do tempo e geral porque ela não se aplica a apenas um evento momentâneo, mas tende a se repetir em outras ocasiões.

Considerando tudo isso, podemos ver que os consumidores têm diferentes atitudes frente aos mais variados tipos de marcas e produtos que lhes são oferecidos, sendo ela capaz de influenciar seus gostos, decisões de consumo e comportamento, sendo este caracterizado por Solomon (2011) como um 
processo no qual indivíduos selecionam, compram, usam e descartam bens e serviços para satisfazerem suas necessidades e desejos. Dessa forma, as atitudes dos consumidores impactam tanto o mercado como a sociedade e parte da responsabilidade de tal fato também pertence às empresas que por meio de suas estratégias de marketing desenvolvem promoções e conceitos a fim de tornar uma ideia em tomada de decisão de consumo, por parte dos indivíduos, resultando em ganhos financeiros para a companhia.

A tomada de decisão de consumo, tida por Solomon (2011) como um processo pelo qual o consumidor reconhece um problema ou necessidade, busca informações a respeito dos produtos disponíveis, considera as alternativas, escolhe qual produto comprar e depois avalia os resultados, pode ser realizada de modo racional e cognitivo, como também instintivo e reforçados por campanhas de promoção que despertam no consumidor a necessidade de possuir tal produto. Sob esta ótica, vemos o quão estratégico é para os profissionais de marketing influenciar as atitudes dos consumidores, ponto também muito importante nesse estudo e que servirá para avaliar os objetivos estabelecidos no capítulo 1 e que serão testados mais adiante, fazendo que comportamentos sejam seguidos e decisões favoráveis às suas vendas sejam tomadas. 


\section{Métodos e procedimentos de coleta e de análise de dados do estudo}

\subsection{Definição e processo de pesquisa}

A nova seção deste trabalho tem como objetivo estabelecer os métodos de pesquisa que serão utilizados, as métricas de avaliação e a retomada das limitações expostas no primeiro capítulo visando validar ou não as hipóteses levantadas neste estudo.

A pesquisa em marketing é definida por Naresh Malhotra (2006) como a identificação, a coleta, a análise e a disseminação sistemática e objetiva das informações. Segundo o autor, a proposta do conjunto dessas ações é melhorar as tomadas de decisão relacionadas à identificação e à solução de problemas existentes em marketing. Majoritariamente, a pesquisa em marketing possui duas possibilidades de aplicação sendo elas: a pesquisa de identificação do problema, que procura avaliar tendências comerciais, previsões, características do mercado dentre outros aspectos, e a pesquisa de solução do problema, que busca trabalhar com questões ligadas à segmentação, distribuição, produto, fixação de preço dentre outras. Malhotra (2006) ao apresentar essas duas classificações ressalta a importância de tratar o termo ou expressão denominados "problema" como oportunidade e é a partir disso que as pesquisas são realizadas a fim de tirar proveito das oportunidades existentes no mercado, partindo de uma visão mais de negócio da utilização da pesquisa em marketing.

Como grande parte dos conceitos apresentados na administração, a pesquisa em marketing também possui um processo bem definido e que sua realização com base neste passo-a-passo aumenta as possibilidades de realizar uma pesquisa bem sucedida e que servirá como base e fundamento para as decisões que serão tomadas como foi sugerido em sua definição. A sequência do processo, bem como a descrição de cada etapa encontra-se a seguir: 
Desenvolvimento da abordagem para o problema

Formulação do projeto de pesquisa

Execução do trabalho de campo e coleta dos dados

\section{Preparação e análise dos dados}

\section{Elaboração e apresentação do relatório}

Figura 2: Processo de pesquisa. - Fonte: Malhotra (2006), "Pesquisa de Marketing", p 7.

A definição do problema corresponde à etapa na qual se estabelece o propósito do estudo e perguntas que nortearão sua execução como, por exemplo, o que levou a realização da pesquisa? Ou ainda o que será feito com os seus resultados? Nela também está presente a avaliação dos dados secundários que são dados coletados de pesquisas feitas com outros propósitos, mas que possuem aplicação prática no problema da pesquisa em execução. $A$ segunda etapa, o desenvolvimento da abordagem para o problema, engloba a estrutura analítica e modelos que serão usados, a especificação das informações necessárias e elaboração de perguntas de pesquisa e testes de hipótese dentre outros pontos, que serviram como referência para a elaboração do questionário que será apresentado mais adiante.

Dando sequência ao processo, na terceira etapa é a formulação do projeto de pesquisa detalhando os procedimentos necessários para obter as informações necessárias. Neste passo, há a definição da escolha por uma pesquisa exploratória, descritiva ou causal, tipos que serão apresentados adequadamente mais adiante, bem como a escolha de fazer uso de pesquisas qualitativas, que mensuram características, atributos e qualidades como o próprio nome sugere, e/ou pesquisas quantitativas, que possuem uma vertente mais numérica e ordinal. A elaboração do questionário também é um item fundamental nesta parte, pois seu encadeamento, sequência das perguntas e 
diversificação nas possibilidades e mensuração de resposta farão com que os resultados do estudo sejam mais ou menos relevantes e confiáveis.

A quarta etapa se trata da execução propriamente dita onde os entrevistadores vão a campo, questionários são enviados e respondidos, técnicas de avaliação e pesquisas são implementadas e há a interação com a amostra previamente estudada e selecionada. A penúltima etapa consiste na separação e análise dos dados obtidos a fim de cruzá-los e traduzi-los em informações importantes e de aplicabilidade ao estudo, além de compará-los com os objetivos estabelecidos nas etapas anteriores. Por fim, a última etapa é a preparação e apresentação do relatório o que representará possibilidades para tomada de decisão e base para pesquisas que possam ser realizadas no futuro e tenham similaridades com o estudo em questão.

Uma pesquisa bem fundamentada e com propósitos e limites bem definidos é importante para a confiabilidade e análise dos resultados que serão apresentados, de modo que torna-se uma tarefa com nível de complexidade maior, mas necessária para a pesquisa realizada. Sem essa coesão e preocupação com o projeto, todos os esforços de uma trabalho poderão ser em vão e inconclusivos.

\subsection{Tipos de pesquisa}

O entendimento e utilização adequada dos tipos de pesquisa existentes são elementos essenciais na etapa 3 do processo de pesquisa, uma vez que é neste passo que se encontra a elaboração do modelo de pesquisa e a escolha do tipo mais adequado permitirá alcançar resultados e observações mais precisas frente ao problema em questão.

Malhotra (2006) classifica os modelos de pesquisa de marketing em dois, sendo eles: o exploratório e o conclusivo. Segundo ele, a pesquisa exploratória é direcionada para buscar mais ideias e informações acerca do problema que está sendo estudado. Nela, a informação necessária é vagamente definida, sua estruturação é bastante flexível e comumente apresenta uma amostra pequena e não-representativa quanto a população pertencente ao problema. Embora muitas vezes seja necessário realizar mais uma pesquisa em seguida a fim de complementá-la, é por meio dela que pesquisadores podem obter os chamados insights necessários para o prosseguimento correto do projeto, pois a estruturação adequada de um plano de pesquisa se torna mais fácil a partir dos esforços da pesquisa exploratória. 
Além dela, temos também a pesquisa conclusiva que, de acordo com o autor, é elaborada para ajudar o tomador de decisão a estipular, avaliar e escolher melhor o curso de ação em uma determinada situação, sendo muitas vezes realizada a fim de colocar em evidência e análise os dados obtidos na pesquisa exploratória. Pode-se afirmar que ela tem a finalidade de testar hipóteses e validar o relacionamento de dados, além de possuir um processo de pesquisa mais estruturado e até formal e suas amostras serem consideradas grandes e representativas, permitindo chegar em resultados finais, conclusivos, como o próprio nome da pesquisa já sugere.

A pesquisa conclusiva pode ainda ser subdividida em descritiva ou causal, onde a primeira visa descrever funções e características do mercado ocorrendo também nela a consideração dos dados secundários, dados de observação, construção de painéis e realização de levantamentos. Malhotra (2006) afirma que os principais estudos descritivos são os estudos de vendas, estudos de percepção e comportamento dos consumidores e estudos de mercado no sentido macroeconômico e externo a empresa. Por outro lado, a causal tem como especialidade verificar a existência de relações de causa e efeito entre variáveis de um modelo, onde a realização desse tipo de pesquisa conclusiva se dá por meio de experimentos que manipulam variáveis consideradas independentes e analisa-se a existência de ligação e influência entre elas.

\subsection{Relevância das entrevistas e do questionário}

Considerando o conteúdo apresentado até então nesse capítulo, a realização de entrevistas com uma gestora da SulAmérica Seguros, Priscila Yabuta, e com um antigo colaborador do Instituto de Resseguros do Brasil, Paulo Tercero, dá conta da necessidade de uma pesquisa qualitativa para este trabalho. Já a elaboração do questionário distribuído para respondentes de forma virtual, completa as possibilidades desse estudo, dentro de suas limitações, com uma pesquisa quantitativa. Tanto as entrevistas como o questionário podem ser classificados como pesquisas conclusivas descritivas que buscarão avaliar as hipóteses levantadas no capítulo primeiro, buscando as respostas com os colaboradores e consumidores do mercado brasileiro de seguros.

Como gestora de uma importante seguradora do mercado brasileiro e que será melhor apresentada no capítulo 4, as palavras de Yabuta são enriquecedoras para o estudo, pois transmitem determinado ponto-de-vista 
acerca do mercado e também passam informações que permitem percebê-la como uma empresa que se preocupa em divulgar sua marca e estar em contato com o cliente, visando suprir suas necessidades. De igual modo, pode-se dizer que o período de atividade de Paulo Tercero, que também será melhor apresentado mais adiante, no setor de seguros lhe dá bastante propriedade para tratar de temáticas que são chave para o desenvolvimento do estudo e suas opiniões, aliadas com a análise do questionário, permitirá um olhar mais completo sobre os resultados obtidos.

\subsection{Detalhes e limitações do Estudo}

A amostra considerada para a realização do trabalho é não-probabilística, ou seja, a amostragem pode ser realizada de acordo com critérios e julgamentos do pesquisador resultando que nem todos os indivíduos de uma população terão a mesma chance de serem pesquisados ou fazerem parte da amostra, segundo Malhotra (2006). Considerando um nível de confiança de 95\% e um erro amostral de $8 \%$, o tamanho buscado para este trabalho será uma amostra de pelo menos 151 pessoas.

Veremos no próximo capítulo que foram registrados 156 respondentes no questionário, alcançando a meta desejada. Além disso, é importante dizer que o questionário, elaborado por meio do Google Formulários e distribuídos por meio de redes sociais através de um link compartilhado, esteve disponível para respostas de 16 a 21 de maio e que a entrevista com a gestora da SulAmérica foi realizada no dia 12 de maio, enquanto o ex-colaborador do Instituto Brasileiro de Resseguros foi entrevistado no dia 17 do mesmo mês. O questionário e o roteiro das entrevistas se encontram nos anexos deste trabalho. 


\section{Apresentação e análise dos resultados}

\subsection{Entrevistas}

Para esta primeira parte da análise da pesquisa, foram realizadas duas entrevistas com um roteiro de perguntas semi-estruturado. A primeira foi com Priscila Yabuta, consultora de controladoria da Vice-Presidência de Planejamento Estratégico e Marketing da SulAmérica Seguros há 3 anos e a outra foi com Paulo Tercero que trabalhou no Instituto de Resseguros do Brasil por 35 anos sendo representante da instituição no Mercado Comum do Sul (Mercosul) e trabalhando na empresa em diversas áreas como assessoria da presidência, coordenação de sinistros, chefia do departamento de direitos comerciais dentre outras atribuições. A relevância dos dois entrevistados para este trabalho se dá pelo fato de um apresentar a visão pertencente a uma grande atuante no mercado e do outro pelos conhecimentos adquiridos ao longo de um grande tempo de trabalho no setor, além da sua instituição manter relação direta com as seguradoras mais importantes do mercado.

O início da entrevista de ambos foi feito por meio da introdução do motivo pelo qual este trabalho está sendo realizado, bem como a apresentação de objetivos já apresentados no capítulo primeiro. Começando pela entrevista com Priscila Yabuta, a primeira pergunta buscou identificar se, na percepção dela, os esforços de marketing vinham evoluindo com o passar dos anos e ela afirmou que quando entrou em 2014 a SulAmérica estava reestruturando sua marca, apresentando uma nova logomarca, nova visão e uma abordagem diferente focando não mais a visão no produto, mas sim no cliente. Parte dessas mudanças pertencem a algo chamado na empresa como Plano de Transformação onde essa remodelação na comunicação e em suas atividades se faz presente tanto internamente como externamente.

A nova abordagem da empresa resultou em mudanças na estratégia de comunicação que, segundo ela, consistem na unificação das formas de anúncio dos variados produtos que a empresa dispõe, abandonando a divulgação de 
maneira separada como era feita anteriormente. Além disso, Priscila Yabuta afirmou, quando perguntada, que a SulAmérica realiza a mensuração dos resultados das suas ações de propaganda de forma conjunta com as agências contratadas, no caso JotaCom e Grey, a fim de se ter uma ideia bastante aproximada de quantas pessoas foram impactadas tanto com os posts realizados nas redes sociais como nos comerciais que foram para outros meios de comunicação como rádio e TV.

Um ponto importante a se destacar é que a SulAmérica havia cortado consideravelmente sua verba para as ações de mídia no ano de 2016 , mas no primeiro trimestre de 2017 voltou a concentrar um investimento mais robusto em campanhas. Atrelado a isso, também foi apresentada uma melhora de quase $10 \%$ em relação ao lucro líquido do mesmo período de 2016 e, quando questionada a respeito disso, a consultora disse com propriedade que acreditava que parte desse bom desempenho era devido a volta da realização das campanhas de mídia, uma vez que a marca voltou a ficar mais exposta e as pessoas tiveram a possibilidade de pesquisar mais a respeito do produtos que foram anunciados pela seguradora.

A respeito do público-alvo da SulAmérica, Yabuta precisou que a empresa concentra seus esforços em pessoas pertencentes às classes $A$ e $B$, tanto que no mapeamento de onde e quando será divulgada a propaganda, o marketing da empresa se preocupa em principalmente atingir pessoas com esse perfil selecionando os canais e horários. Outra questão importante foi quanto à sua opinião em relação a um possível pensamento existente em determinadas partes da sociedade brasileira que consideram o seguro como algo típico a pessoas de mais idade e ela afirmou que parte disso se deve a um pensamento pertencente ao passado, mas que se pode enxergar uma mudança quanto a adesão de seguros nas mais diversas idades, já que jovem tem contratado seguros de viagem para realização de "mochilões", além de rever conceitos com relação à previdência privada, uma vez que a reforma na previdência pública brasileira é questão de pouco tempo para ser feita.

Por último, com relação à estratégia da SulAmérica frente aos concorrentes, ela afirma que como forma de reagir às seguradoras emergentes e que tem ganhado espaço no mercado, a empresa tem feito planos chamados "Compactos" para tentar conquistar e manter parte dessa parcela do mercado, apesar de não ser o público-alvo da companhia. Também é possível ver no relatório anual divulgado pela empresa o crescimento dos investimentos em 
cross-selling ${ }^{1}$ visando que o cliente adquira todos os tipos de seguros oferecidos pela empresa e minimizando que ele adquira um tipo de seguro com a SulAmérica e outro com uma seguradora concorrente.

A outra entrevista realizada com Paulo Tercero abordou pontos similares e outros complementares até então. Tercero acredita que ao longo do tempo que trabalhou no IRB ele pôde verificar uma mudança na consciência do consumidor brasileiro quanto a seguros, aumentando a importância da prevenção em vez de fazê-lo apenas quando já estava em uma situação de grande risco. Esse avanço permitiu, segundo ele, uma tendência a redução do preço do seguro, uma vez que mais pessoas passariam a tê-lo. Todavia, o aumento de sinistros, muitas vezes causados pelo aumento da violência, não confirmaram essa tendência, principalmente com o seguro de automóveis, que muitos só costumam fazer por estar em uma área de grande risco. Continuando sua opinião com relação ao perfil do consumidor frente aos tipos de seguro, o antigo representante do IRB no Mercosul também acredita que com o aumento da propaganda sobre 0 seguro de vida ajudou a mudar a mentalidade do consumidor brasileiro que antes era muito mais avesso a pensar sobre a morte ou deixar um prêmio de seguro para alguém.

Quanto ao seguro residencial, ele acredita que apesar de ser muito importante e barato, o corretor não vê tanta vantagem em comercializá-lo e concentra seus esforços nos outros tipos considerados mais rentáveis. Apesar da mudança ser vagarosa, Tercero reitera que ela pode ser considerada grande se comparada a tempos anteriores e também com outros países onde a ideia do seguro já é melhor aceita. Partindo para a importância do resseguro, que consiste em ser um instrumento no qual há propriamente a realização de um seguro sobre outro seguro já existente, Paulo Tercero defende a ideia de que ele serve para aumentar as possibilidades de negócio visto que dá uma capacidade extra já que tipicamente o mercado brasileiro de seguros possui uma capacidade considerada restrita por ele, principalmente para grandes riscos.

Quando questionado sobre a divulgação e propagandas de seguros no Brasil, ele fala que as campanhas poderiam ser mais realistas em detrimento do que elas acabam dando quando o segurando precisa utilizar o seguro. Tercero aponta o seguro de vida como um nicho importante no qual ele acredita ainda ser comum ver as seguradoras fazendo anúncios contendo pessoas mais velhas e voltados para elas, sendo que se pessoas mais jovens o fizessem teriam a

1 Cross-selling: técnica de venda que estimula o cliente a adquirir produtos complementares ao produto inicial adquirido. 
oportunidade de pagar muito menos e contribuir para com a seguradora por muito mais tempo. O antigo colaborador do IRB pensa um pouco diferente de Priscila Yabuta, já que ele considera que uma boa parcela ainda vê o seguro com algo voltado para pessoas de mais idade.

Um ponto em comum com Yabuta, Tercero defende que é necessário incluir pessoas mais jovens na massa de segurados da empresa pela oportunidade de cobrar um prêmio mais barato tendo em vista a possibilidade de contar com esse dinheiro por muito mais tempo, já que a possibilidade de ocorrência de sinistro é baixa. Paulo Tercero encerra sugerindo que seja incluída a comparação do montante de seguros em relação o PIB total de países da Europa e também dos EUA com a relação existente entre seguros e o PIB brasileiro e também que seguro não é algo que dá prejuízo e deve ser visto como uma reserva na qual a gordura acumulada pelo tempo de adesão compensa os momentos de necessidade do seguro.

\subsection{Descrição do perfil da amostra}

Esta parte da seção é referente a dados demográficos que são importantes para analisar o nível de heterogeneidade da amostra. Eles foram colocados por último porque são dados onde acredita-se que os respondentes não tem que pensar muito para responder e no qual o seu nível de atenção já encontra-se menor nesta fase do questionário. A seguir, teremos os dados relativos a faixa etária, escolaridade e renda média mensal familiar:

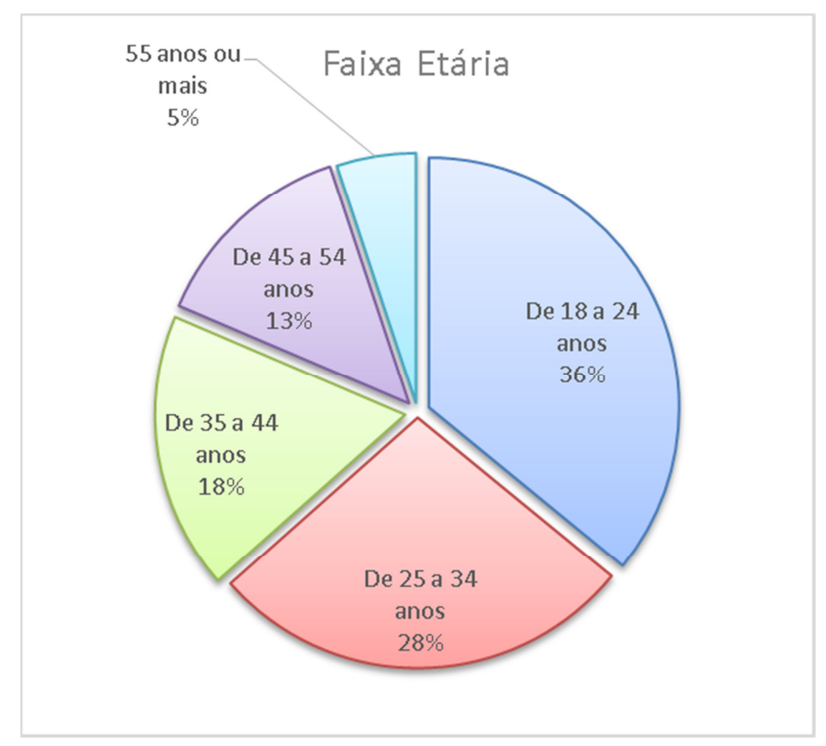

\footnotetext{
Gráfico 1: Composição etária da amostra: aproximadamente $64 \%$ dos respondentes tem entre 18 e 34 anos
} 
A amostra contou com uma distribuição de faixa etária com certa concentração em pessoas entre 18 e 34 anos, representando aproximados $64 \%$ das respostas. A divisão pelas faixas disponíveis foi feita levando em consideração que de 18 a 24 anos as pessoas estão buscando entrar e se manter no mercado de trabalho, participando de processos seletivos e assumindo inicialmente cargos mais operacionais e, também pela sua pouca ou nenhuma experiência, ganhando menos. Dos 25 aos 34 anos as pessoas em geral já apresentam uma experiência profissional, a qual permite também traçar planos pessoais mais concretos como comprar um imóvel, acumular uma parte maior da renda para certos projetos e até mesmo se casar.

O cidadão médio de 35 a 44 anos tende a possuir já uma família, ainda que pequena até pelas mudanças culturais que são percebidas nas sociedades contemporâneas. Acima dos 45 aos 54 , acredita-se as pessoas já possuam uma vida mais estável, com filhos já numa certa idade e se preparando mais intensamente para a aposentadoria, o que se também pode ser percebido na faixa etária das pessoas com pessoas acima dos 55 anos, mas, na maioria das famílias, essas pessoas já possuem filhos entrando na faixa etária de buscar seu emprego e obter sua própria renda.

Sob a ótica da escolaridade, a amostra teve $79 \%$ dos respondentes com o ensino médio ou ensino superior completos. Vale destacar que alguns provavelmente já estejam na universidade, mas ainda não tenham completado o curso e outros que já estejam numa pós-graduação ainda não concluída. A abertura para níveis incompletos, pelo menos inicialmente, não parecia ser essencial e, dessa forma, não foi utilizada, uma vez que com a distribuição proposta já seria possível fazer análises eficazes.

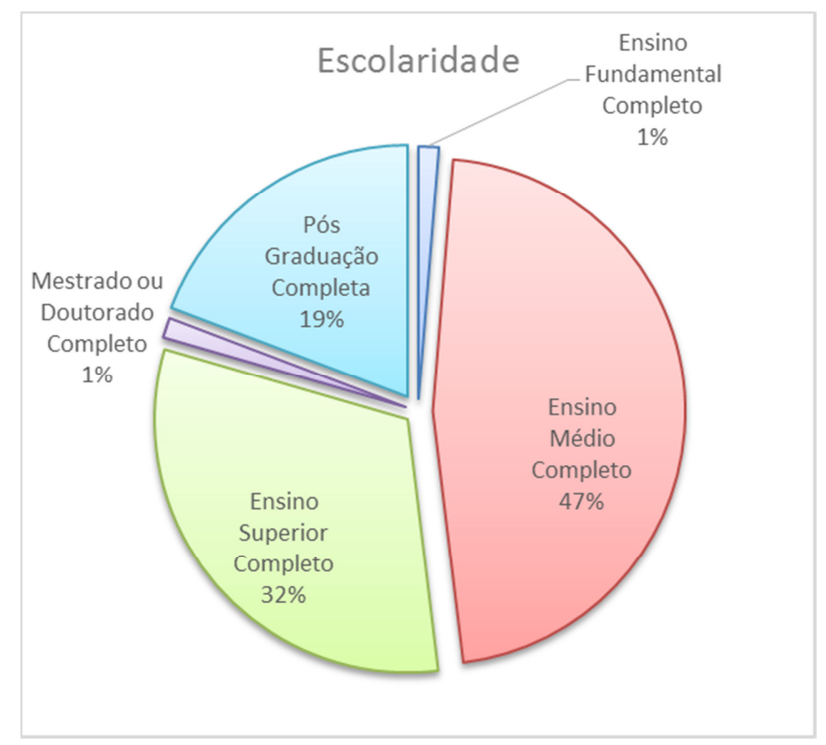

Gráfico 2: Escolaridade da amostra:

47\% têm pelo menos o Ensino Médio completo 
Por fim, o último critério abordado foi a faixa de renda e, utilizando os critérios do Instituto Brasileiro de Geografia e Estatística com base na divisão pela quantidade de salários mínimos, podemos observar que a maioria das opiniões vieram de pessoas pertencentes às classes $C$ e $D$ que juntas somam $63 \%$.

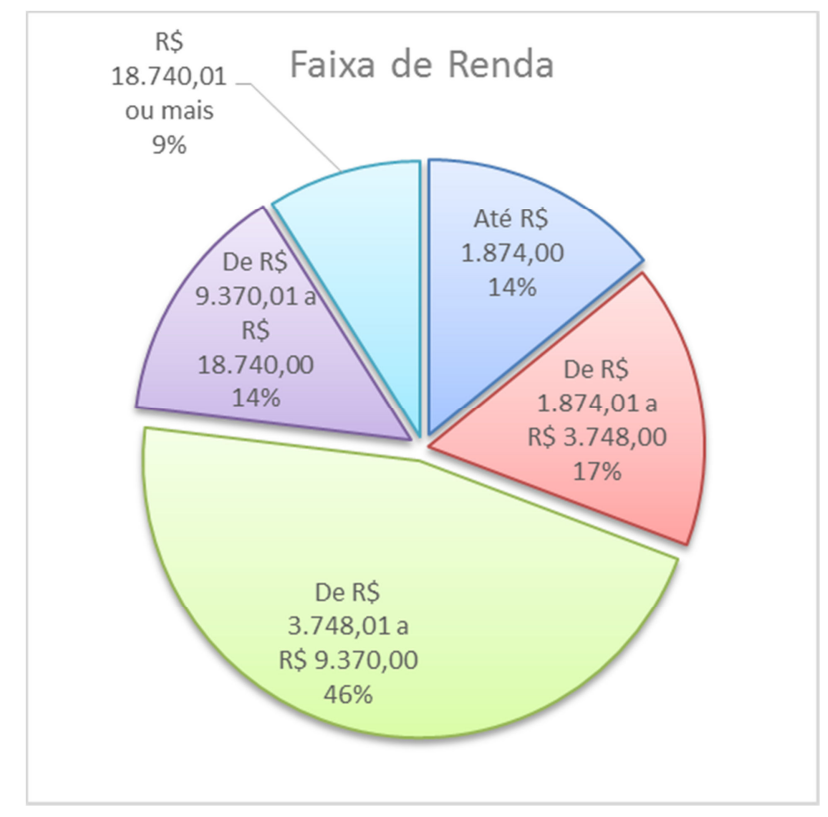

Gráfico 3: Distribuição de renda da amostra: $46 \%$ são da Classe C

As faixas do IBGE são: até 2 salários mínimos (Classe E), de 2 a 4 salários mínimos (Classe D), de 4 a 10 salários mínimos (Classe C), de 10 a 20 salários (Classe B) e acima de 20 salários (Classe A). Uma subdivisão na classe C também era possível usando os outros critérios que fazem distinção entre classes C1 e C2, mas também não foi visto como imprescindível para a pesquisa, bem como para análise dos resultados.

\subsection{Questionário}

Reforçando o que já foi dito anteriormente, com o intuito de complementar as informações obtidas nas entrevistas, este questionário foi desenvolvido para verificar também a percepção e reconhecimento das marcas de seguradoras por parte dos respondentes. Ao todo, foram 156 pessoas que fizeram sua contribuição e o detalhamento da amostra dela se encontra na parte final. Como forma de entendermos o porquê as perguntas foram realizadas, bem como as respectivas respostas, o questionário será exposto de forma linear a seguir. Para 
visualizá-lo da mesma forma que os respondentes, ele está disponível na parte de anexos deste trabalho.

\subsubsection{Questões introdutórias}

A primeira pergunta foi "Para você, quais são as principais seguradoras do mercado brasileiro atualmente?" e as respostas eram abertas, sem opções previamente dadas com o objetivo de forçar o respondente a trazer de sua memória as primeiras marcas que vinham em sua mente com a instrução de que escrevessem pelo menos três, mas alguns colocaram até mais.

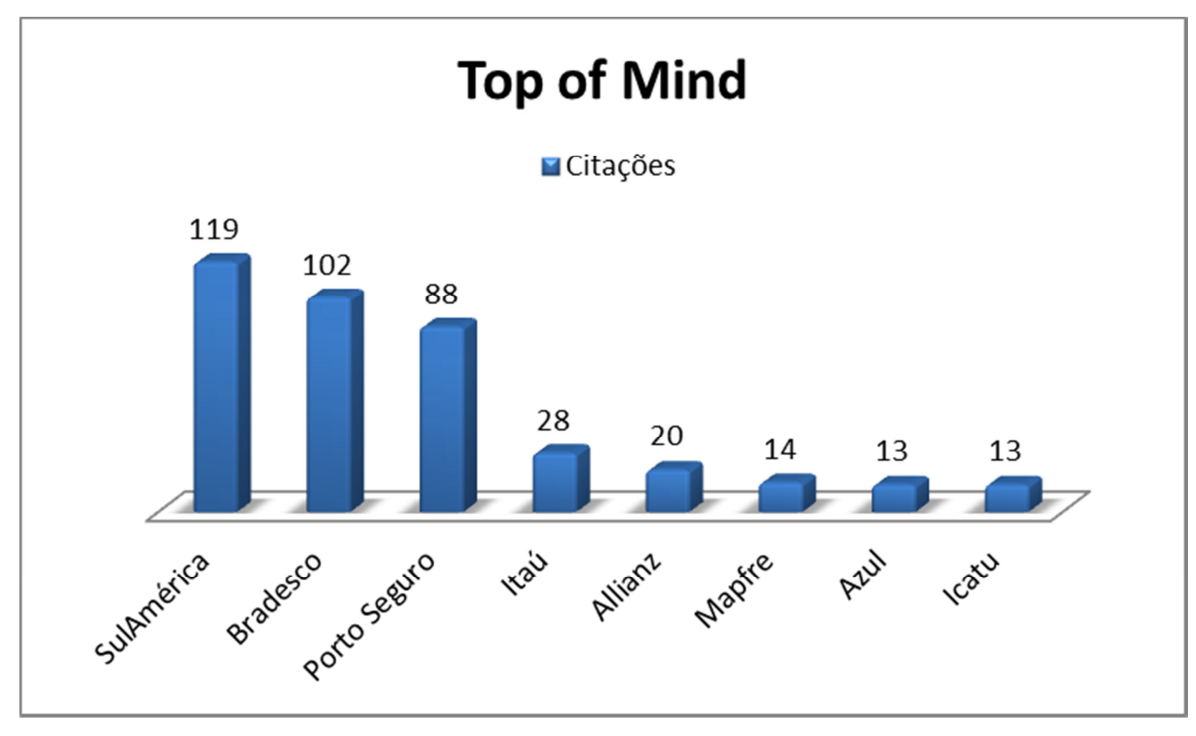

Gráfico 4: Top of Mind: as marcas mais lembradas foram SulAmérica, Bradesco e Porto Seguro.

A empresa que teve mais citações foi a SulAmérica seguida de perto pela Bradesco e também pela Porto Seguro. Ao todo foram registradas 491 citações e, na imagem contendo o Top of Mind, vemos apenas as empresas que totalizam $80 \%$ citações. É importante destacar que empresas de saúde também foram mencionadas, até mais que propriamente seguradoras, com a Amil com 15 lembranças e a Unimed com 12, mas que por sua natureza não foram inclusas na imagem. 


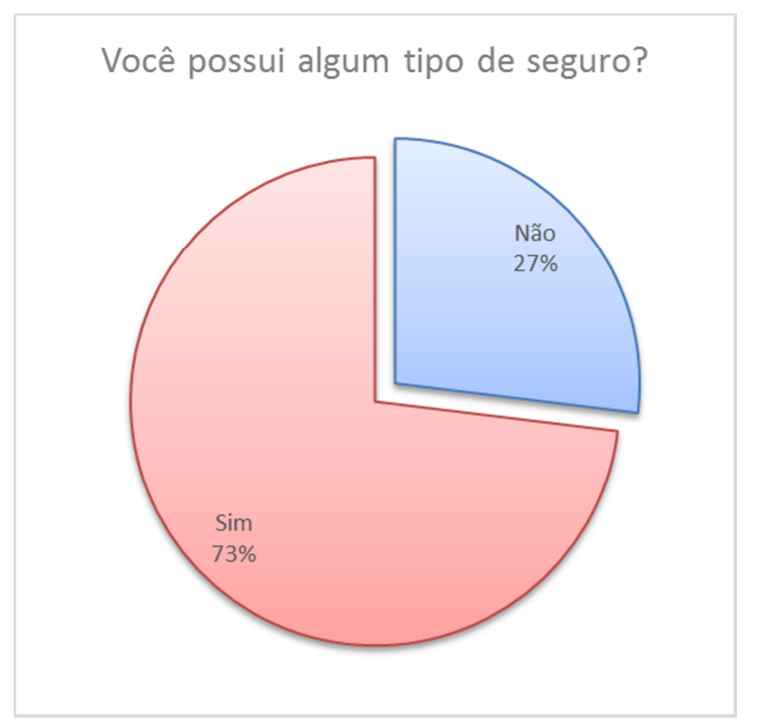

Gráfico 5: Respondentes com seguros: $73 \%$ da amostra possui algum tipo de seguro.

Em seguida, perguntou-se se o respondente possuía algum tipo de seguro e podemos ver que $73 \%$ da amostra consultada tinha pelo menos um seguro, enquanto $27 \%$ não possuem. Os que responderam afirmativamente ainda puseram a qual seguradora o produto que usavam pertencia, sendo majoritariamente de uma mesma que já haviam citado anteriormente. Também se eram eles mesmos que adquiriram e/ou realizaram os pagamentos havendo 68 respostas sim e 88 respostas não. Das pessoas que responderam não, apenas 54 disseram quem cumpria então esse papel tendo um destaque de 32 respostas para "pai, mãe ou responsável".

Mais um aspecto presente no mercado brasileiro de seguros é o baixo percentual da população que possui pelo menos um tipo de seguro. De acordo com a Federação Nacional de Previdência Privada e Vida (FenaPrevi), em 2014 apenas $18 \%$ dos brasileiros tinham algum tipo de seguro e, para verificar na amostra se ainda havia uma percepção do seguro como um produto importante, foi realizada a seguinte pergunta: "Na sua opinião, os seguros são importantes para as pessoas da nossa sociedade nos dias de hoje?". O resultado afirmativo foi muito expressivo, 95\%, como podemos ver na imagem abaixo. 


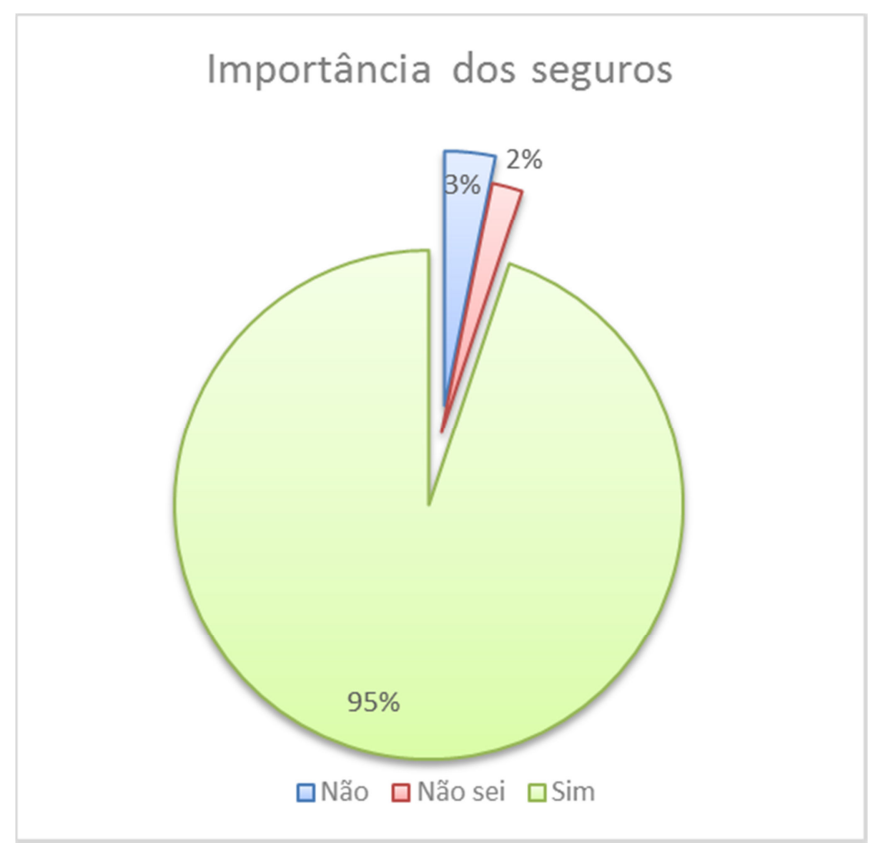

\section{Gráfico 6: Importância dos seguros: 95\% dos respondentes consideram o seguro como um produto importante}

Esse resultado vai ao encontro do que Paulo Tercero afirmou sendo uma mudança na mentalidade do brasileiro com relação à importância de possuir um seguro que, apesar de ser vagarosa, se faz presente e crescente nos dias de hoje. Todavia, o que pode talvez justificar a ciência da importância de um seguro mas isso não se refletir em mais aquisições do produto é o período econômico de dificuldade que o Brasil atravessa no momento, aliado pelo fato dos seguros ainda possuírem um valor relativamente alto, dada a grande quantidade de sinistros que ocorrem, muitos atribuídos ao elevado índice de violência que o Rio de Janeiro, bem como o Brasil apresenta em relação a outras localidades no mundo, como sugere a entrevista com Tercero.

Outra questão que foi averiguada era de um possível pensamento existente na mente em muitos consumidores brasileiros onde acreditava-se que o seguro era tipicamente um produto atrelado a pessoas de mais idade e a sua necessidade se fazia notada a partir dessa etapa da vida. Para tentar avaliar, foi inserida uma questão na qual havia duas afirmações, onde na primeira o seguro era algo que devia ser adquirido pelas pessoas quando elas têm mais idade e a segunda era o seguro como algo que devia ser adquirido desde a juventude das pessoas. Em ambas o respondente possuía uma escala de resposta que podia ser "discordo totalmente", "discordo parcialmente", "concordo parcialmente" e "concordo totalmente" e os resultados obtidos na amostra mostram uma consciência da importância do seguro como algo que devia ser adquirido desde quando as pessoas são novas e tem a oportunidade de planejar sua vida e não 
quando são de mais idade onde teoricamente teriam mais recursos financeiros e estabilidade para adquirir seguros.

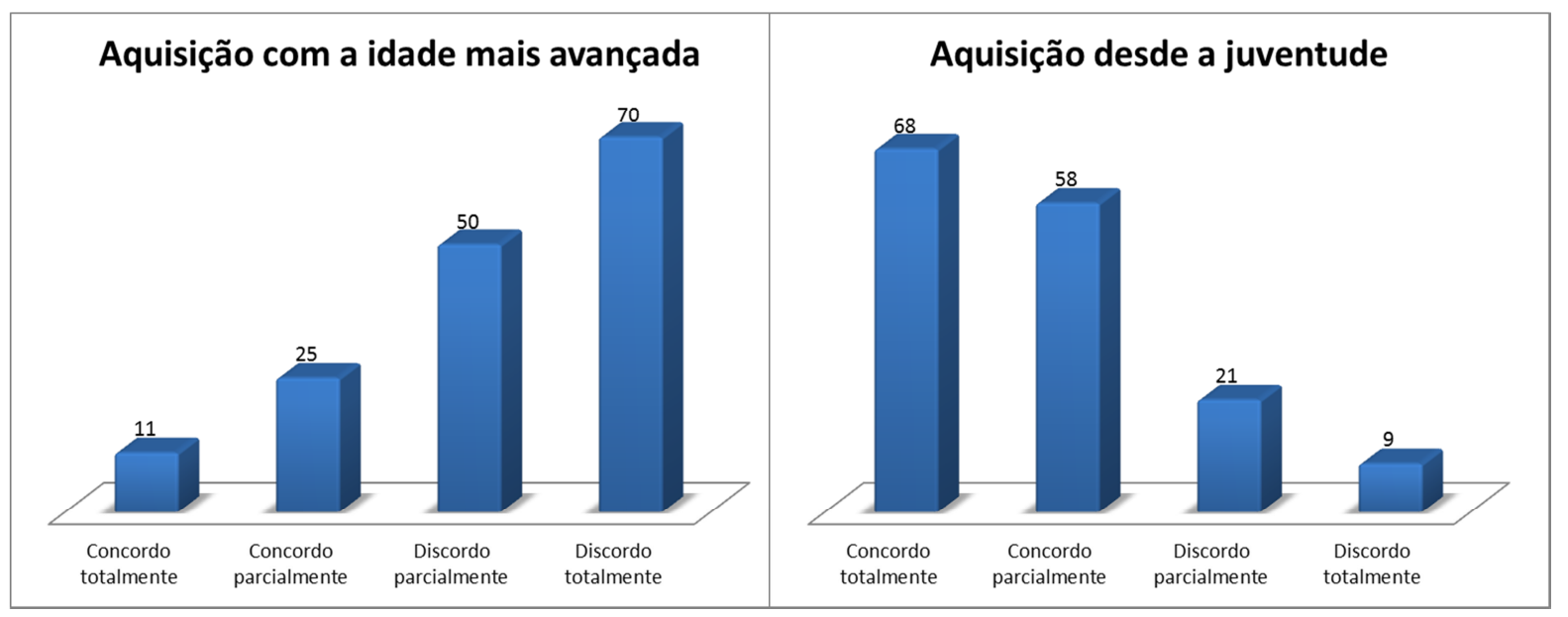

Gráfico 7: Momento de aquisição: A amostra acredita que o seguro deve ser adquirido desde a juventude.

Essa visão está alinhada com o que Priscila Yabuta afirmou com relação a aquisição de seguros por parte de pessoas mais novas, ainda não sejam necessariamente os tidos como mais clássicos como seguros de vida ou residencial e sim para viagens, mas isso pode significar uma preocupação maior com o futuro e uma consciência voltada para o planejamento da vida, algo muito associado com o que ela disse a respeito da procura das pessoas por plano de previdência privada tendo em vista que uma reforma na previdência brasileira se aproxima.

Esses dados também mostram uma tendência para mudança na abordagem das seguradoras o que já tem sido visto em algumas de suas campanhas fazendo um apelo mais descontraído, leve e algumas vezes até cômico. Isso tende a abandonar a visão citada por Paulo Tercero na qual muitos anúncios antes mostravam pessoas bem idosas e em situações quase que terminais para apresentar o seguro como um produto oportuno para aquele momento.

Além de avaliar a percepção dos consumidores considerando a natureza do seguro, a pesquisa também procurou destacar alguns pontos que são considerados na aquisição e uso do seguro. Para tentar dar conta de mais este aspecto, foi feita para a amostra a seguinte pergunta: "Na sua opinião, qual o grau de importância dos seguintes atributos em um seguro?". Como opções de resposta e avaliação, foram considerados os aspectos "Ampla Rede Referenciada", "Boa Reputação no Mercado", "Facilidade de Aquisição e Uso", 
"Preço", "Qualidade", Recomendação de Pessoas de Confiança" e "Segurança". O respondente poderia eleger numa escala de 1 a 7 qual era a importância de cada atributo considerando 1 como menos importante e 7 como mais importante.

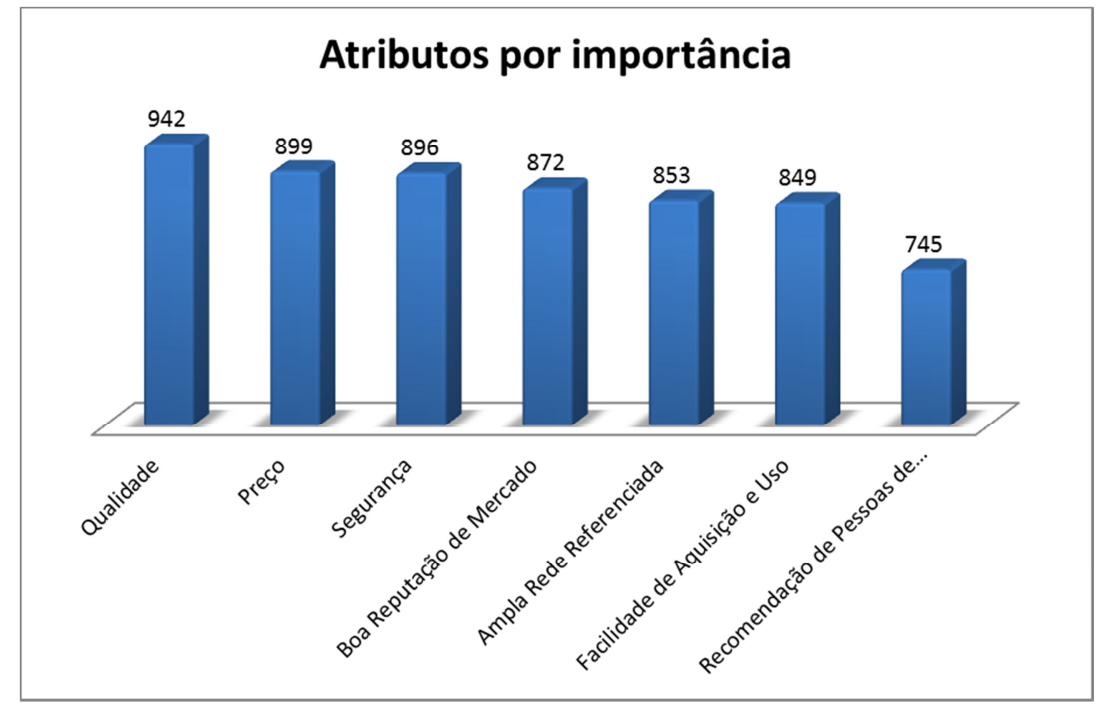

Gráfico 8: Atributos de um seguro: a amostra prioriza a qualidade do seguro

A imagem com os resultados mostra uma atenção maior dos entrevistados pela qualidade presente no seguro que, apesar de ser até certo ponto relativa e variar de acordo com a percepção, é possível imaginar a decepção de um consumidor que realiza os pagamentos sempre em dia e quando mais precisar do seguro ficar desapontado quanto a resolução da sua necessidade naquele momento. Em seguida, vieram os atributos preço e segurança com uma diferença bem pequena, sugerindo uma busca por estabilidade e custo-benefício diante do momento econômico e político pelo qual nosso país está atravessando. Estes resultaram foram obtidos por meio da soma de todas as classificações feitas pelos respondentes.

Para fechar a primeira seção do questionário, a última questão tinha o objetivo de verificar se as pessoas que responderam o questionário conheciam o processo para a contratação de seguro e o resultado foi até satisfatório. Aproximadamente $63 \%$ das respostas, ou seja, 99 de 156, marcaram o processo "Cotação com Corretor - Formulário - Análise da Seguradora - Apólice de Seguro - Uso do Seguro" como a opção certa e, embora esteja bem resumida, a sequência das etapas sugere a ordem que as seguradoras costumam adotar. A segunda sequência mais marcada foi "Formulário - Cotação com Corretor Apólice de Seguro - Análise da Seguradora - Uso do Seguro" com quase 24\% das opiniões. 


\subsubsection{Teste de lembrança}

A segunda seção do questionário tinha o propósito de testar a lembrança dos consumidores frente a cores e slogans das seguradoras e na primeira pergunta as pessoas deviam escolher a qual empresa pertencia o anúncio abaixo.

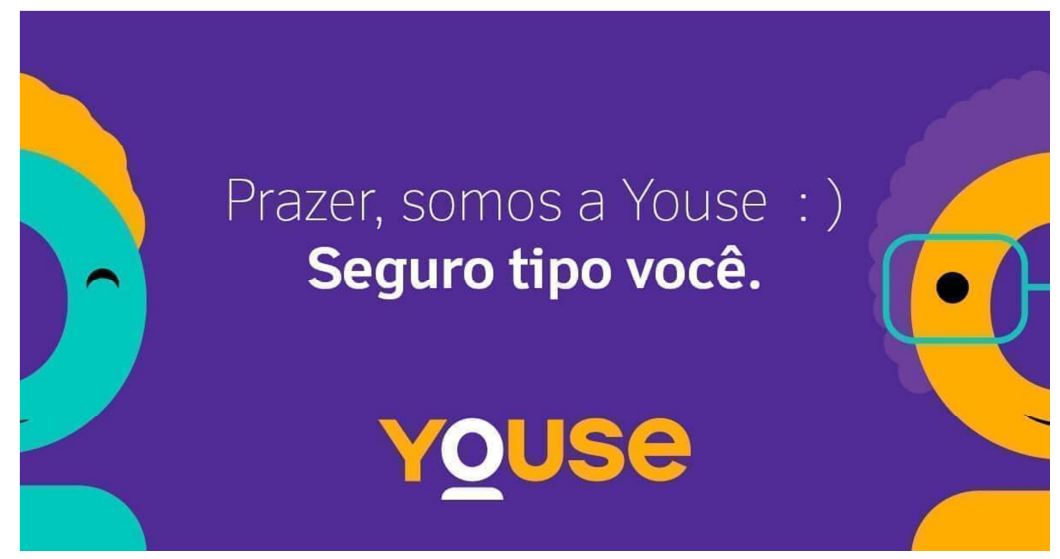

Figura 3: Anúncio de apresentação da Youse, plataforma de vendas da Caixa Seguradora.

A Youse, como já dito anteriormente, é uma plataforma de vendas de seguros da Caixa Seguradora e que tem como principal virtude permitir que o consumidor possa resolver, segundo ela, absolutamente tudo pelo smartphone. Porém, diante das opções possíveis, as $67 \%$ das pessoas acreditaram que este anúncio pertencia a Liberty Seguros, enquanto a Caixa Seguradora levou apenas $25 \%$ dos votos.

A questão seguinte, por outro lado, demonstrou um resultado bem melhor. Considerando a imagem com um carro entre os traços brancos e o fundo vermelho, 154 das 156 respostas foram acertadamente para a Bradesco Seguros, representando quase $99 \%$ das opiniões e destacando o bom conhecimento das pessoas com relação à identidade visual caraterística à companhia.

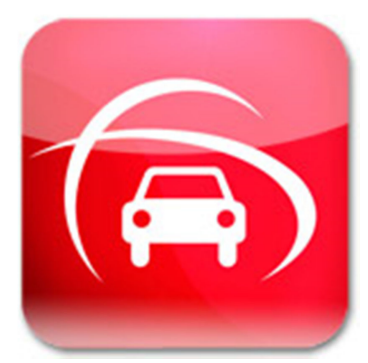

Figura 4: Seguro automotivo

Bradesco no teste de lembrança. 
Na terceira questão da segunda seção, a imagem apresentada continha o seguinte slogan"Há 120 anos a vida é imprevisível e, acredite, isso é muito bom." que foi usado pela SulAmérica na época na qual a companhia estava comemorando 120 anos de atuação no mercado brasileiro. Parte da redefinição da marca e da renovação da identidade visual dita por Priscila Yabuta anteriormente podem ser percebidas nesse anúncio. A imagem apresentada para os respondentes foi a seguinte:

\section{HÁ 120 ANOS, \\ A VIDA É IMPREVISIVEL \\ E. ACREDITE, ISSO É MUITO BOM.}

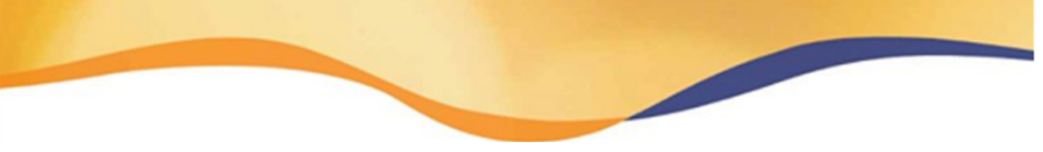

Figura 5: Slogan e cores da SulAmérica no teste de lembrança.

O resultado obtido foi favorável dado que 104 das 156 opiniões foram para a empresa de cores predominantes azul e laranja. Isso significa que quase $67 \%$ das respostas reconheceram às características pertencentes à SulAmérica, enquanto a segunda opção mais marcada, a Icatu Seguros, alcançou quase $13 \%$.

O último teste da seção correspondia aos respondentes marcarem a opção que completava corretamente o slogan promovido pela Mapfre Seguros que continua sendo utilizado até este período no qual este trabalho está sendo executado. A instrução era "Complete o seguinte slogan de uma seguradora: "Mas se tem tem jeito." e cerca de $54 \%$ das pessoas marcaram a opção correta com 85 cliques. Em segundo lugar apareceu a seguradora do Itaú com 35 votos, ou seja, quase $22 \%$. 


\subsubsection{Avaliação de anúncios}

A terceira seção contemplava as seguintes imagens nas quais as pessoas, considerando que elas não tivessem seguros, deviam marcar com base nelas qual seguradora contratariam, qual não contratariam, qual achavam pertencer ao público de mais idade e qual pertencia ao público mais jovem além de dizer o porquê de sua opinião.

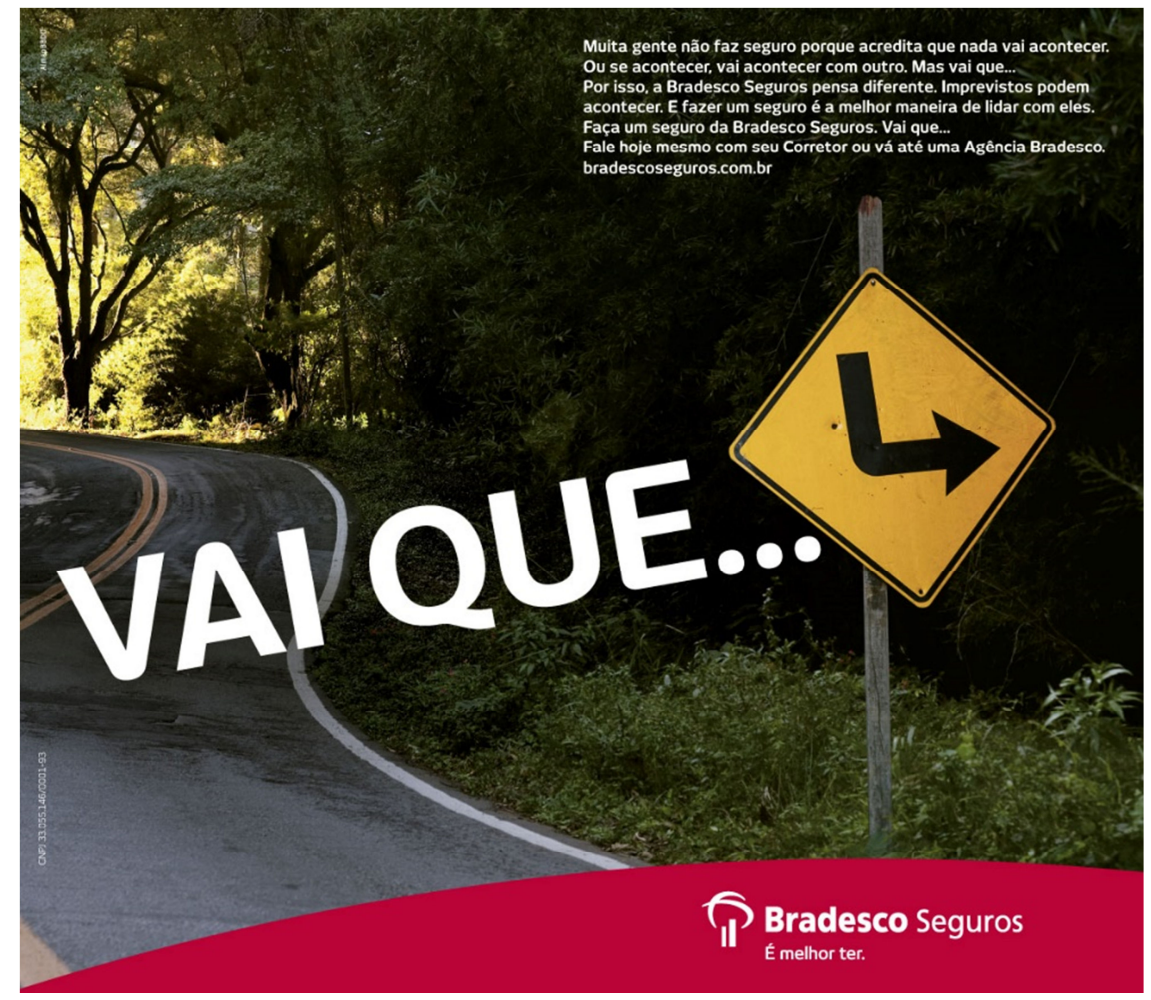

Figura 6: Anúncio da Bradesco.

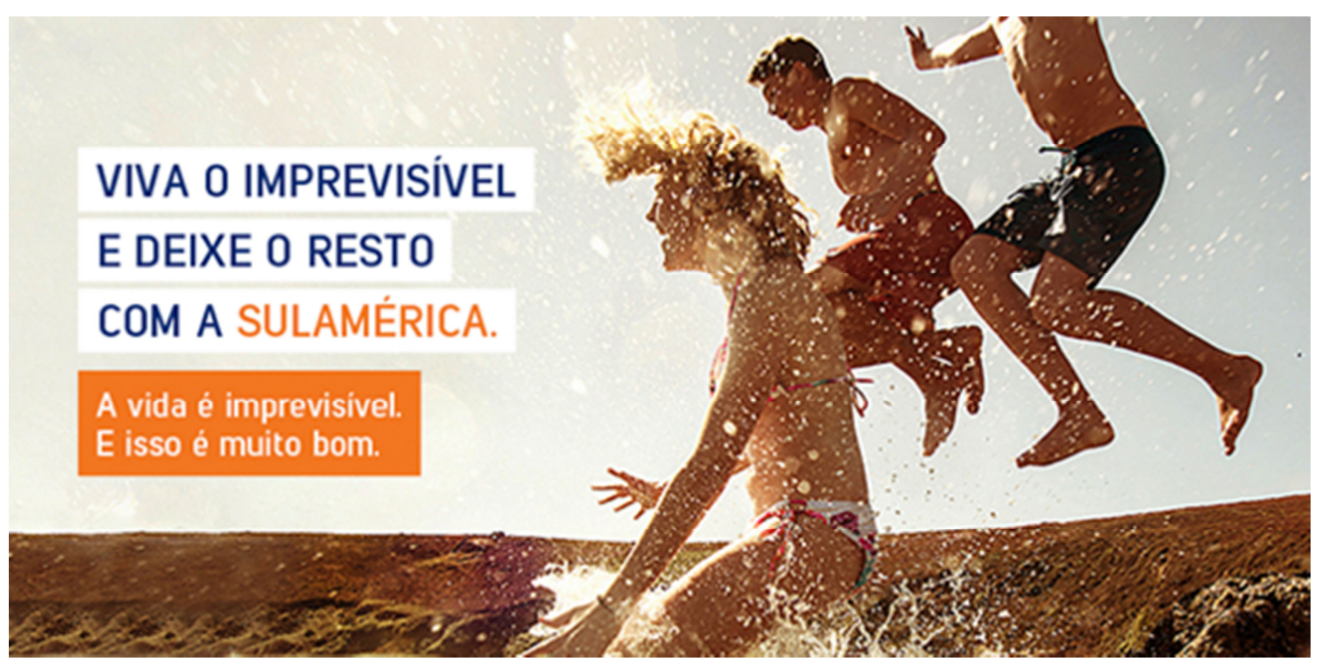

Figura 7: Anúncio da SulAmérica. 


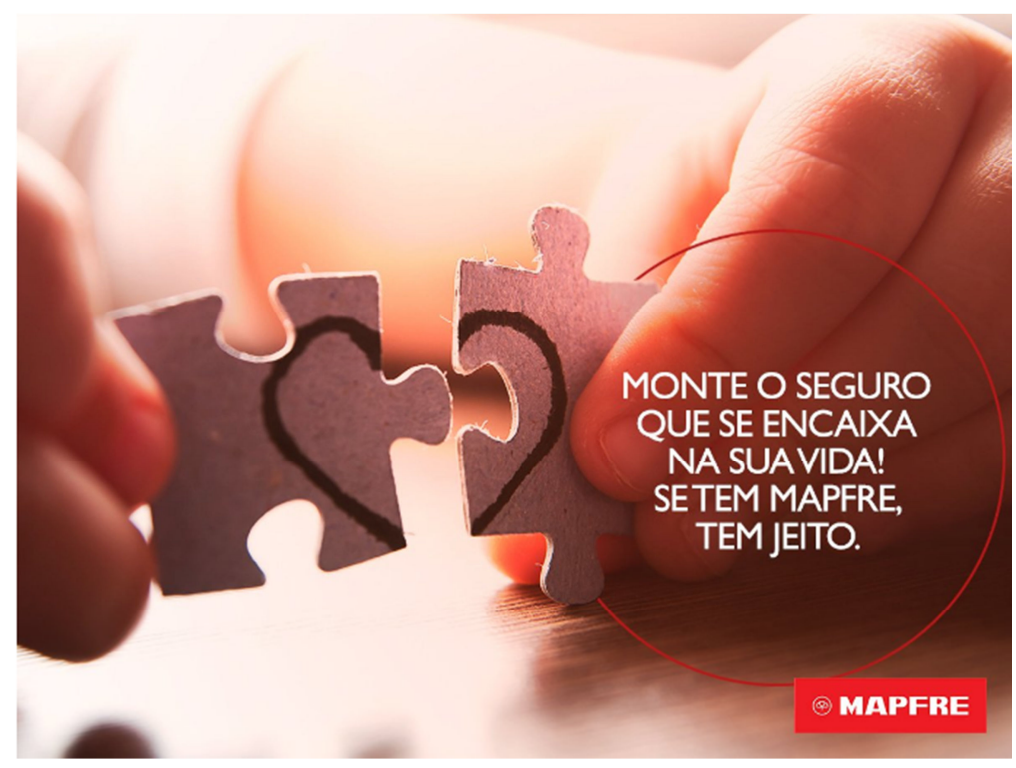

Figura 8: Anúncio da Banco do Brasil Mapfre.

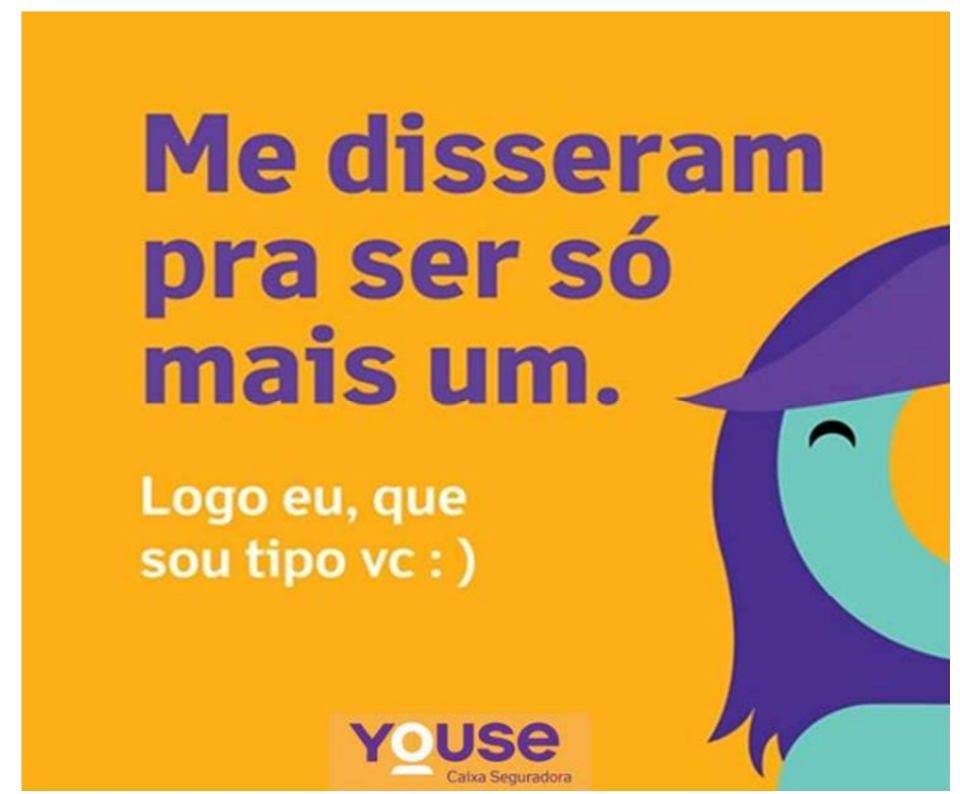

Figura 9: Anúncio da Youse Caixa Seguradora.

Considerando a limitação das imagens, uma vez que possuem pouca informação a respeito da parte técnica de um seguro, bem como o fato de não terem sido selecionadas pelas próprias seguradoras para representá-las na pesquisa, embora tenham sido divulgadas por elas mesmas, e também por terem sido apresentadas na ordem que as empresas aparecem por participação 
de mercado em 2016, segundo o Sindicato de Corretores do Rio de Janeiro, foram obtidos os seguintes resultados:

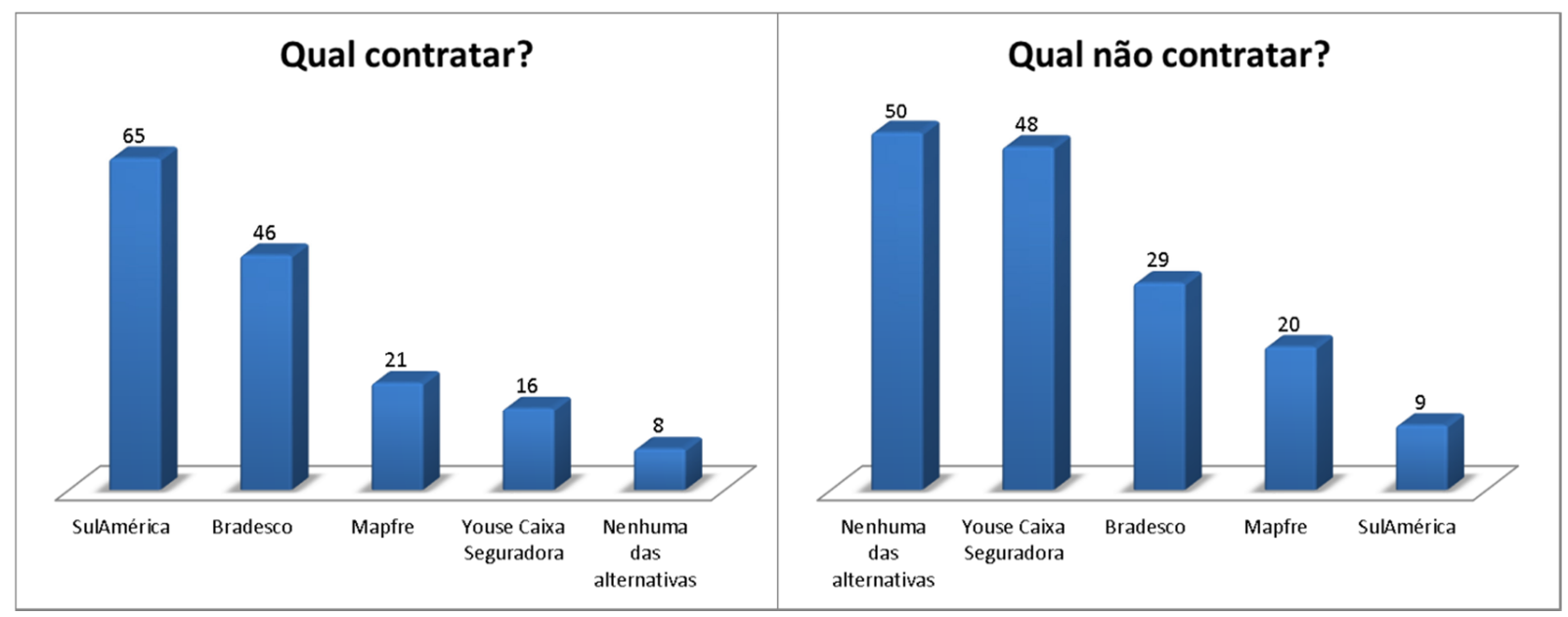

Gráfico 9: Contratação de seguradora: Com base nos anúncios, qual seguradora seria contratada ou não.

Quando a questão foi contratação, a SulAmérica e a Bradesco somaram juntas mais de $71 \%$ das escolhas. Nas justificativas das escolhas, muitas pessoas transcenderam as campanhas que estavam expostas, já que além de uns apreciarem o lado cômico da Bradesco e o destaque para aproveitar o lado bom do imprevisível na vida das pessoas pela SulAmérica, foram feitas menções a respeito do conhecimento anterior da marca, boas experiências quando usaram os produtos dessas empresas e ressaltaram aspectos ligados a estabilidade e tempo de mercado, bem como solidez e confiança, remetendo ao atributos destacados na primeira seção do questionário e reforçando a coesão das respostas. Objetividade e uma abordagem mais leve também foram apontados.

Continuando, quando questionadas sobre qual seguradora não contratariam, a maioria apontou que não viram motivos para deixar de contratar alguma seguradora especificamente e uma das justificativas que mais apareceu foi o fato do conhecimento prévio das marcas antes de responder o questionário o que fariam com que pudessem considerar todas as alternativas apresentadas e escolhesse aquela que apresentasse algum diferencial. Em segundo lugar, quase que empatada aparece a Youse Caixa Seguradora e as justificativas para não contratação variam desde não achar que passou a mesma credibilidade que as outras, ou ainda que não havia necessariamente comunicado algo, até a associações com ações da Caixa como um banco afirmando que é uma 
instituição muito burocrática, onde as experiências de uso com seus produtos não são das melhores e pelo fato de ser pública associá-la às instabilidades políticas que tem sido tão abordadas ultimamente.

Por fim, visando avaliar alguma relação existente dos anúncios com um público de idade mais específica, constatamos que os respondentes perceberam o anúncio da Mapfre Seguros mais voltado para pessoas de mais idade e podese ver nas justificativas que, por fazer uma abordagem um pouco mais formal que as demais, além de ser das cores e de uma linguagem mais séria, segundo as opiniões das pessoas, teve essa classificação. Por outro lado, a SulAmérica Seguros e a Youse Caixa Seguradora juntas foram percebidas por 119 pessoas da amostra como as que tiveram anúncios que melhor falaram com o público mais jovem. A maioria das respostas mostra que essa percepção é devida à linguagem mais informal e característica da internet por parte da Youse além de cores menos tradicionais em anúncios de seguros. Somam-se a essas considerações, as opiniões de que a SulAmérica Seguros com a sua abordagem pelo imprevisível e conter jovens no anúncio a fizeram como a que melhor falou com o público mais jovem.

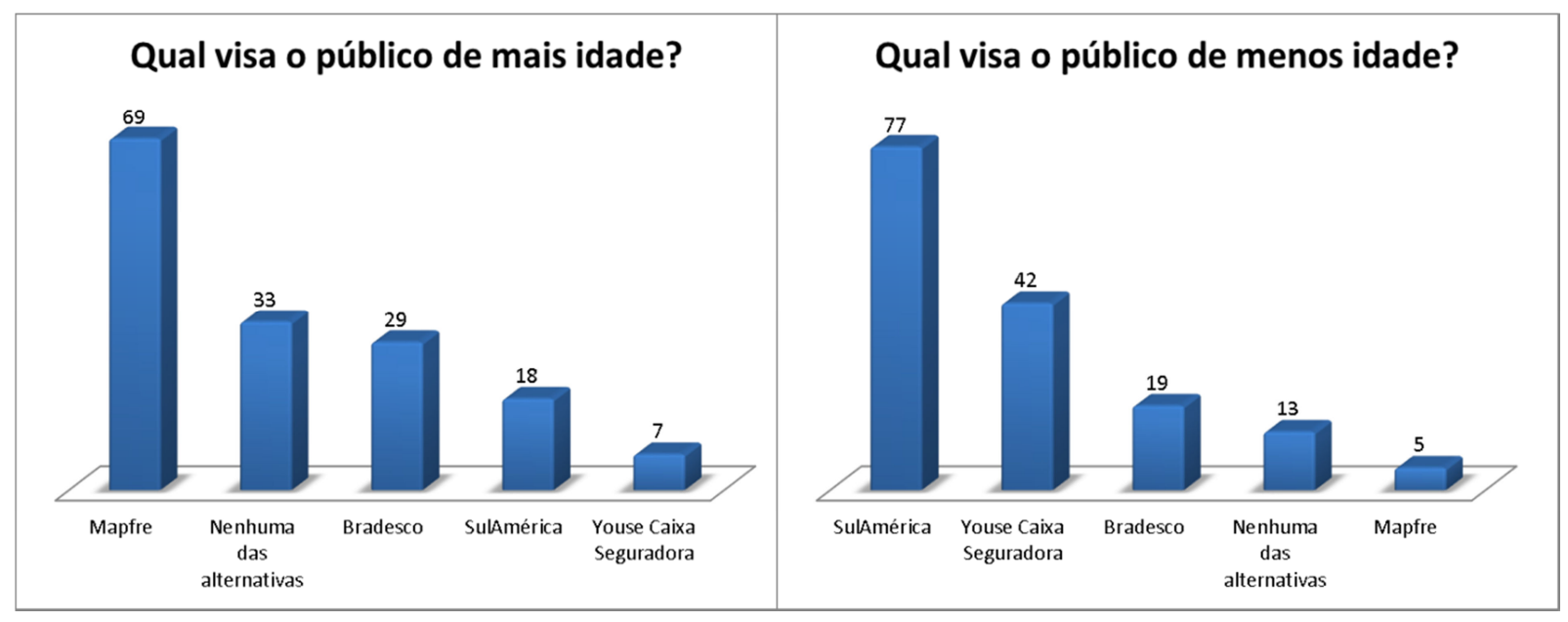

Gráfico 10: Público-alvo das seguradoras: Com base nos anúncios, qual a seguradora que visou mais o público de mais ou de menos idade. 


\section{Conclusões e recomendações para novos estudos}

No primeiro capítulo deste estudo, foi feita uma breve contextualização acerca do mercado de seguros e de sua importância para o mercado brasileiro. Além disso, foram apresentados os objetivos intermediários, os quais visavam avaliar a relação dos consumidores com as marcas das seguradoras e o objetivo final que é avaliar se vale a pena continuar destinando parte consideráveis do orçamento de uma seguradora em promoção e divulgação da marca, mesmo em momentos de instabilidade econômica como a qual o nosso país atravessa no momento. Dentre as pretensões do trabalho, também estão presentes as limitações, que o fazem ser bem específico, todavia com utilidade e relevância para academia e para as empresas do setor que desejarem utilizá-lo, como demonstrado em seguida.

No segundo capítulo, está a revisão de leitura proposta para compreender as questões trabalhadas no estudo. Diretamente relacionado com os resultados e importante para as ações de uma companhia, o brand equity é importante para dimensionar e avaliar as ações de comunicação integrada, verificando se estão impactando positiva ou negativamente o valor da marca. Complementares e essenciais em um estudo de comunicação, a inserção do posicionamento, da publicidade, da gestão do relacionamento com o cliente e a atitude do consumidor também fizeram parte desta seção.

A experiência na realização das entrevistas e na elaboração do questionário também foi bem proveitosa, já que foi mais uma oportunidade de acompanhar o andamento para o alcance dos propósitos deste trabalho e colocá-los verdadeiramente teste a fim de averiguar a consistência do raciocínio desenvolvido até então, bem como perceber contribuições e possibilidades de análise que iam além do planejamento inicial. A qualidade das entrevistas concedidas, os conhecimentos dos entrevistados, além da contribuição dos respondentes nas questões abertas do questionário foram de grande proveito.

Foi possível verificar na realização da pesquisa que, por meio do relacionamento que os respondentes tiveram com as marcas, seja utilizando experiências passadas e fazendo referência a uma lealdade existente, ou porque 
já tinham ouvido falar da marca e tinham uma opinião dela, vimos que esses elementos permitiram que eles fizessem uma boa avaliação, sobretudo das seguradoras Bradesco e SulAmérica, uma vez que, segundo eles, são empresas que traduzem solidez e segurança fazendo com que pudessem contratar os serviços dessas instituições caso necessitassem. Este dado tem relação com o fato delas serem empresas que possuem os maiores investimentos em divulgação no mercado segurador, bem como as maiores participações de mercado em 2016 segundo o Sindicato dos Corretores do Rio de Janeiro. Dessa forma, Bradesco e SulAmérica comprovam aquilo que foi apresentado por Al Ries e Laura Ries em As 22 Consagradas Leis de Marcas onde, por já terem conhecimento do mercado e estarem solidificadas nele, é necessário investimento em propaganda para manter a participação de mercado conquistada e até crescer.

Foi percebido também que a Youse, apesar de tentar uma nova abordagem por meio de uma linguagem não muito característica do mercado segurados, não teve uma boa aceitação, talvez pelas características mais conservadoras do mercado que até certo ponto consideram campanhas que tratem com humor a necessidade do seguro como fez a Bradesco Seguros, ou ainda apelando para um slogan mais descontraído de viver o imprevisível como fez a SulAmérica Seguros, mas uma linguagem coloquial não propriamente atraiu tanto os mais jovens que foram mais representativos na composição da amostra.

Diante de tudo isso, a ciência de que vale a pena investir em propaganda, mesmo em períodos de recessão como o qual nosso país está passando, mostra-se muito importante e, para validar esse pensamento, é necessário verificar regularmente os impactos dessas ações. É com base nisso que Crescitelli e Shimp (2012) afirmam que ainda que sua precisão não seja total, é melhor fazê-lo e estar vagamente certo do que precisamente errado.

Por fim, considerando o que foi apresentado e as limitações já expostas, pode-se concluir que, mesmo em cenários macroeconômicos adversos, vale a pena continuar destinando uma parte representativa do orçamento para esforços de marketing e divulgação. Também que há elevação do brand equity das marcas em estudo que realizam investimentos relevantes em promoção, sendo importante para elas no relacionamento com os consumidores e impactando positivamente o retorno financeiro dessas ações. Uma vez que as marcas das seguradoras, graças às suas campanhas, são reconhecidas, elas possuem mais oportunidades de atrair clientes e continuar gerando receita em períodos de crise 
que é um momento também propício para um produto como o seguro, facilitando o desenvolvimento das ações que mantenham esse cliente fidelizado por mais um tempo e possibilitem o retorno almejado pela seguradora para atravessar 0 período controverso.

Além desta conclusão, é válido esperar que este trabalho possa servir como fonte de consulta para estudos posteriores que abordem os esforços de marketing no mercado segurador brasileiro, de modo que mais conhecimento possa ser gerado levando em conta as características distintas deste setor que possui importância para a economia brasileira. 


\section{Referências Bibliográficas}

AAKER, D. Marcas: Brand Equity - Gerenciando o Valor da Marca. 11ª ed., Elsevier, 1998.

CASTELLS, Manuel. A Era da Informação: economia, sociedade e cultura, vol. 3, São Paulo: Paz e terra, 1999.

CRESCITELLI, E. ; SHIMP, T. A. Comunicação de marketing. São Paulo: Cengage, 2012.

KOTLER, P. ; KELLER, K.L. Administração de marketing. 13a. ed. São Paulo: Prentice Hall, 2009.

LEVITT, T. A Imaginação de Marketing. São Paulo: Atlas, 1991.

MALHOTRA, N. K. Pesquisa de marketing: uma orientação aplicada. Porto Alegre: Editora Bookman, 2006.

RIES, Al.; RIES, Laura. As 22 consagradas leis de marcas. São Paulo: Makron Books, 2000.

RIES, Al ; TROUT, Jack. Posicionamento: a batalha por sua mente. 20a ed. São Paulo: Makron Books, 2002.

ROCHA, Everardo P. G. Magia e Capitalismo: um estudo antropológico da publicidade. São Paulo: Brasiliense, 1990.

SOBRAL, F; PECl, A. Administração: teoria e prática no contexto brasileiro.; São Paulo: Pearson, 2012.

SOLOMON, Michael R. O Comportamento do Consumidor: Comprando,

Possuindo e Sendo. Porto Alegre, Editora Bookman, 2011. 


\section{Anexo 1 - Perguntas das Entrevistas}

Perguntas da entrevista com Priscila Yabuta:

1 - Qual seu cargo, sua área e há quanto tempo você está na SulAmérica?

2- Com relação à SulAmérica, você tem visto que os esforços de marketing tem evoluído à medida que o tempo tem passado desde que você entrou na empresa?

3 - Como você avalia o Plano de Transformação da SulAmérica, tanto internamente como externamente, e relacionando-o com o marketing da companhia?

4 - Você acredita que a SulAmérica realiza uma mensuração dos esforços de marketing e avalia os impactos de suas campanhas?

5 - Na sua opinião, o bom resultado que a SulAmérica apresentou no primeiro trimestre de 2017 aumentando sua receita de vendas e o lucro líquido em comparação com o mesmo período do ano passado tem a ver com o aumento dos investimentos em campanhas de mídia que a companhia fez?

6 - Quanto ao consumidor do mercado de seguros, como que o planejamento estratégico e o marketing da SulAmérica o enxerga hoje?

7 - Como você identifica o público-alvo da SulAmérica?

8 - Você acredita que os consumidores do mercado brasileiro pensam o seguro como um produto para pessoas mais velhas, os tidos como "pais de família" ou algo parecido?

9 - Como a SulAmérica enxerga seus principais concorrentes no cenário atual? No que eles se igualam e no que eles se diferenciam com relação à companhia? 
Perguntas da entrevista com Paulo Tercero:

1 - Quanto tempo o senhor trabalhou no IRB? Em quais cargos e áreas?

2 - Qual foi sua relação com o Mercosul representando o IRB?

3 - Como o senhor vê o produto do seguro no Brasil atualmente?

4 - Qual o perfil do consumidor brasileiro com relação ao mercado de seguros?

5 - E a comparação é com outros países para os exemplos dos tipos de seguro que o senhor descreveu?

6 - Quais seguradoras tinham uma proximidade maior com o IRB?

7 - Qual a importância do resseguro para o mercado de seguros em geral?

8 - Pelo conhecimento que o senhor adquiriu ao longo desses anos no setor, o senhor acredita que as seguradoras fazem anúncios de forma adequada?

9 - O senhor acredita que as pessoas pensam o seguro como um produto para pessoas de mais idade? 


\section{Anexo 2 - Questionário}

\section{Mercado Brasileiro de Seguros}

Seção 1 de 4

\section{Questões Introdutórias}

Prezado respondente,

Este questionário tem como objetivo coletar informações acerca dos usos e preferências dos consumidores em relação ao mercado de seguros brasileiro a fim de serem utilizadas em um estudo para o departamento de Administração da PUC-Rio. Sua colaboração é muito bem-vinda e essencial para a execução deste trabalho. O preenchimento deste questionário é anônimo e confidencial.

Desde já, muito obrigado!

1 - Para você, quais são as principais seguradoras do mercado brasileiro atualmente? (Por favor, liste as 3 primeiras que vem à memória)

2 - Você possui algum tipo de seguro? (ex: saúde, odontológico, automotivo, residencial, de vida...)
[ ] Sim
[ ] Não

Se sim, de qual ou quais empresas?

3 - Foi você mesmo que os adquiriu e/ou realiza os pagamentos?
[ ] Sim
[ ] Não 
Se não, quem?

\section{[ ]1.Cônjuge}

[ ] 2.Pai / Mãe / Responsável

[ ] 3.Filho (a)

[ ] 4.Irmão (a)

[ ] 5.Outro

4 - Na sua opinião, os seguros são importantes para as pessoas da nossa sociedade nos dias de hoje?
[ ] Sim
[ ] Não
[ ] Não sei

De acordo com o que você pensa, o seguro é:

a) Algo que deve ser adquirido pelas pessoas quando elas já tem mais idade

[ ] Discordo totalmente

[ ] Discordo parcialmente

[ ] Concordo parcialmente

[ ] Concordo totalmente

b) Algo que deve ser adquirido pelas pessoas desde a juventude delas

[ ] Discordo totalmente

[ ] Discordo parcialmente

[ ] Concordo parcialmente

[ ] Concordo totalmente

5 - Na sua opinião, qual o grau de importância dos seguintes atributos em um seguro? Por favor, considere de 1 (menos importante) a 7 (mais importante) e marque apenas um por coluna.

Ampla Rede Referenciada

[ ]1/[ ]2/[ ]3/[ ]4/[ ]5/[ ]6/[ ]7 
Boa Reputação de Mercado

[ ]1/[ ]2/[ ]3/[ ]4/[ ]5/[ ]6/[ ]7

Facilidade de Aquisição e Uso

[ ]1/[ ]2/[ ]3/[ ]4/[ ]5/[ ]6/[ ]7

Preço

[ ]1/[ ]2/[ ]3/[ ]4/[ ]5/[ ]6/[ ]7

Qualidade

[ ]1/[ ]2/[ ]3/[ ]4/[ ]5/[ ]6/[ ]7

Recomendação de Pessoas de Confiança

[ ]1/[ ]2/[ ]3/[ ]4/[ ]5/[ ]6/[ ]7

Segurança

[ ]1/[ ]2/[ ]3/[ ]4/[ ]5/[ ]6/[ ]7

6 - Marque o processo que você acredita ser o utilizado na contratação de um seguro:

[ ] Formulário - Cotação com Corretor - Apólice de Seguro - Análise da Seguradora - Uso do Seguro

[ ] Cotação com Corretor - Formulário - Análise da Seguradora - Apólice de Seguro - Uso do Seguro

[ ] Uso do Seguro - Formulário - Apólice de Seguro - Cotação com Corretor Análise da Seguradora

[ ] Apólice de Seguro - Cotação com Corretor- Análise da Seguradora Formulário - Uso do Seguro 
Seção 2 de 4

\section{Avaliação de lembrança das marcas}

Item 1: Anúncio da Youse Caixa Seguradora.

O anúncio acima (item 1) pertence a qual empresa?

[ ] SulAmérica Seguros

[ ] Caixa Seguradora

[ ] Liberty Seguros

[ ] Bradesco Seguros

Item 2: Seguro Automotivo Bradesco.

O seguro automotivo acima (item 2) pertence a qual empresa?

[ ] Porto Seguro

[ ] Liberty Seguros

[ ] Bradesco Seguros

[ ] Icatu Seguros

Item 3: Imagem com cores e slogan SulAmérica.

O slogan e as cores do anúncio acima (item 3) são de qual empresa?

[ ] Mapfre Seguros

[ ] Porto Seguro

[ ] Icatu Seguros

[ ] SulAmérica Seguros

Item 4: Complete o seguinte slogan de uma seguradora: "Mas se tem tem jeito."

[ ] Mapfre

[ ] Itaú

[ ] Liberty

[ ] Caixa 
Seção 3 de 4

\section{Avaliação de anúncios}

ATENÇÃO: As campanhas a seguir podem servir como respostas para as questões da seção anterior. Por favor, não volte pois a avaliação da lembrança da marca é um dado muito importante para o estudo e a alteração das respostas pode comprometer e invalidar todos os esforços até aqui. Muito obrigado!

Considere as seguintes campanhas para responder as próximas perguntas:
a) Campanha Bradesco
b) Campanha SulAmérica
c) Campanha Mapfre
d) Campanha Youse Caixa Seguradora

Supondo que você não tenha nenhum seguro e considerando as campanhas vistas, com qual você contrataria um seguro?

[ ] Bradesco

[ ] SulAmérica

[ ] Mapfre

[ ] Youse Caixa Seguradora

[ ] Nenhuma das alternativas

Por quê?

Qual você não contrataria?

[ ] Bradesco

[ ] SulAmérica

[ ] Mapfre

[ ] Youse Caixa Seguradora

[ ] Não percebi nenhum motivo para deixar de contratar alguma 
Por quê?

Qual campanha está relacionada ao público de mais idade?

\section{[ ] Bradesco}

[ ] SulAmérica

[ ] Mapfre

[ ] Youse Caixa Seguradora

[ ] Nenhuma das alternativas

Por quê?

Qual campanha está relacionada ao público mais jovem?
[ ] Bradesco
[ ] SulAmérica
[ ] Mapfre
[ ] Youse Caixa Seguradora
[ ] Nenhuma das alternativas

Por quê? 
Seção 4 de 4

Informações Demográficas

Relembrando: todas as respostas são anônimas e confidenciais.

1 - Quantos anos você tem?

[ ] Até 17 anos

[ ] De 18 a 24 anos

[ ] De 25 a 34 anos

[ ] De 35 a 44 anos

[ ] De 45 a 54 anos

[ ] 55 anos ou mais

2 - Qual sua escolaridade?

[ ] Ensino Fundamental Incompleto

[ ] Ensino Fundamental Completo

[ ] Ensino Médio Completo

[ ] Ensino Superior Completo

[ ] Pós Graduação Completa

[ ] Mestrado ou Doutorado Completo

3 - Qual a renda mensal da sua família?

[ ] Até $\mathrm{R} \$ 1.874,00$

[ ] De $R \$ 1.874,01$ a $R \$ 3.748,00$

[ ] De $\mathrm{R} \$ 3.748,01$ a $\mathrm{R} \$ 9.370,00$

[ ] De $R \$ 9.370,01$ a $R \$ 18.740,00$

[ ] $\mathrm{R} \$ 18.740,01$ ou mais 